\title{
Petrologia e geocronologia (U/Pb-Sm/Nd) do Granito Passagem, Complexo Granitóide Pensamiento, SW do Cráton Amazônico (MT)
}

\author{
Gisely Carmo de Jesus ${ }^{1}$, Maria Zélia Aguiar de Sousa ${ }^{2}$, Amarildo Salina Ruiz ${ }^{3}$ \& \\ João Batista de Matos ${ }^{3}$
}

\begin{abstract}
Resumo O granito Passagem compreende stocks, plugs e diques localizados na Serra de Ricardo Franco - município de Vila Bela da Santíssima Trindade - Mato Grosso, pertencentes ao Terreno Paraguá, SW do cráton Amazônico. Constitui-se de monzo a sienogranitos e, mais raramente granodioritos, isotrópicos, leucocráticos de cor cinza-escuro até branco e textura preferencialmente equigranular hipidiomórfica a inequigranular xenomórfica, fina a média, tendo biotita como único mineral máfico primário essencial. Essas rochas caracterizam uma seqüência ácida pouco expandida formada por um magmatismo sub-alcalino do tipo cálcio-alcalino de alto potássio, levemente peraluminoso, gerado em ambiente de arco magmático provavelmente em época pós-colisional. Mecanismo de cristalização fracionada de plagioclásio, biotita, titanita, apatita e zircão associado à concomitante assimilação crustal são sugeridos para a evolução dessas rochas. Os resultados aqui obtidos reforçam a hipótese de um magmatismo pós-colisional no Terreno Paraguá com idade de $1284 \pm 20$ Ma correspondendo à cristalização do Granito Passagem e permite reconhecê-lo como prolongamento, em terreno brasileiro, do Complexo granitóide Pensamiento.
\end{abstract}

Palavras-chave: Granito Passagem, petrologia e geocronologia, Complexo Granitóide Pensamiento, Terreno Paraguá.

\begin{abstract}
Petrography and geochronology (U/Pb-Sm/Nd) the Passagem Granite, Pensamiento Granitoid Complex, Paraguá Terrane, SW amazonian Craton, Mato Grosso, Brazil. The Passagem granite includes stocks, plugs and dikes located in the Ricardo Franco hill - Vila Bela da Santissima Trindade region -state of Mato Grosso, central Brazil. The Passagem Granite is included in the Paraguá terrane - SW Amazonian Craton. It consists of isotropic monzogranite, sienogranite and more rarely granodiorites with leucocratic dark gray to white color. These rocks range from hypidomorphic inequigranular to xenomorphic texture, fine to medium grained. Biotite is the only primary mafic present as essential phase and characterize an expanded slightly acid sequence formed by a sub-alkaline magmatism of high-potassium calc-alkaline, slightly peraluminous composition from arc magmatic tectonic environment during a post-collisional period. Mechanism of fractional crystallization of plagioclase, biotite, titanite, apatite and zircon associated with simultaneous crustal assimilation are suggested for the evolution of these rocks. The results support the hypothesis of a post-collisional magmatism in the Paraguá terrane at $1284 \pm 20 \mathrm{Ma}$ corresponding to the crystallization age of the Passagem granite. This paper propose that Passagem Granite represents as an extension in Brazilian terrane of the Pensamiento Granitoid Complex.
\end{abstract}

Keywords: Passagem Granite, Petrology and Geochronology, Pensamiento Granitoid Complex, Paraguá Terrane.

INTRODUÇÃ̃o A região fronteiriça do estado de Mato Grosso com a Bolívia, sudoeste do cráton Amazônico, é pouco estudada sob o ponto de vista geológico, apesar de muito interessante por apresentar registro de grande quantidade de rochas magmáticas ácida a intermediária. A principal documentação disponível corresponde, no Brasil, a trabalhos publicados pelos Projetos RADAMBRASIL (Santos et al. 1979, Barros et al. 1982) e algumas monografias de conclusão de curso da Universidade Federal de Mato Grosso e, na Bolívia, ao Projecto Precambrico (1986) e artigos mais recentes com enfoque geocronológico e geotectônico de Boger et al. (2005), Santos et al. (2008), Ruiz (2009), Matos et al. (2009) e Bettencourt et al. (2010).

A área estudada localiza-se nas proximidades da
Serra de Ricardo Franco, no município de Vila Bela da Santíssima Trindade, no Terreno Paraguá (Ruiz 2009, Bettencourt et al. 2010). Não apresenta registros deformacionais e metamórficos da orogenia Sunsás $(1.1$ a $0.95 \mathrm{Ga})$ correspondendo ao prolongamento, no Brasil, do Complexo Granítico Pensamiento constituído por terrenos granítico-gnáissicos expostos no oriente boliviano. Este trabalho compreende dados obtidos a partir do mapeamento geológico na escala de 1:80.000, envolvendo caracterização petrográfica, geoquímica e geocronológica do granito Passagem, representante do magmatismo tardi a pós-tectônico da Orogenia San Ignácio (1.37 a 1.3 Ga).

CONTEXTO GEOLÓGICO REGIONAL O cráton Amazônico é estruturado em diversas Províncias Geo-

1 - Universidade Federal de Mato Grosso (UFMT), Instituto de Ciências Exatas e da Terra - (ICET), Programa de Pós-Graduação em Geociências, Cuiabá (MT), Brasil. E-mail: giselycarmo@hotmail.com

2 - UFMT, ICET, Departamento de Recursos Minerais. E-mail: mzaguiar@terra.com.br

3 - UFMT, ICET, Departamento de Geologia Geral. E-mail: asruiz@gmail.com; jmatos@cpd.ufmt.br 
cronológicas-Tectônicas que retratam sucessivas acresções continentais a partir de um núcleo arqueano (Cordani et al. 1979, Teixeira \& Tassinari 1984, Tassinari \& Macambira 1999, Tassinari et al. 2000 e 2004, Geraldes 2000, Santos et al. 2000, 2008, Ruiz 2005, Cordani \& Teixeira 2007). Das compartimentações recentemente publicadas notam-se diversas discrepâncias quanto à definição dos limites temporais e físicos das Províncias Geocronológicas, assim como quanto à nomenclatura utilizada para as mesmas (ex. Geraldes 2000, Tassinari et al. 2004, Ruiz 2005, Santos et al. 2000, 2008). A área estudada situa-se no contexto da Província RondonianaSan Ignácio, considerada a proposta de Ruiz (2005) onde o Bloco Rio Apa, exposto no Mato Grosso do Sul e Para- guai, constitui o extremo sul deste cráton (Fig. 1).

O sudoeste do cráton Amazônico em Mato Grosso e no oriente boliviano tem sido estudado sistematicamente desde as décadas de 70/80, resultando diversas propostas de compartimentação geológica-tectônica (Tab. 1). Adotase neste trabalho aquela sugerida por Ruiz (2009) que, com base na evolução geológica que antecede a orogenia Sunsás (1.0 a $0.85 \mathrm{Ga})$, divide a região em três principais blocos crustais denominados: Terreno Paraguá, Terreno Rio Alegre e Terreno Jauru (Fig. 2).

O Terreno Paraguá, onde se situa a área estudada (Fig. 2), aflora em duas principais regiões em Mato Grosso, nas imediações das serras de Santa Bárbara e Ricardo Franco, sendo a área investigada localizada nas

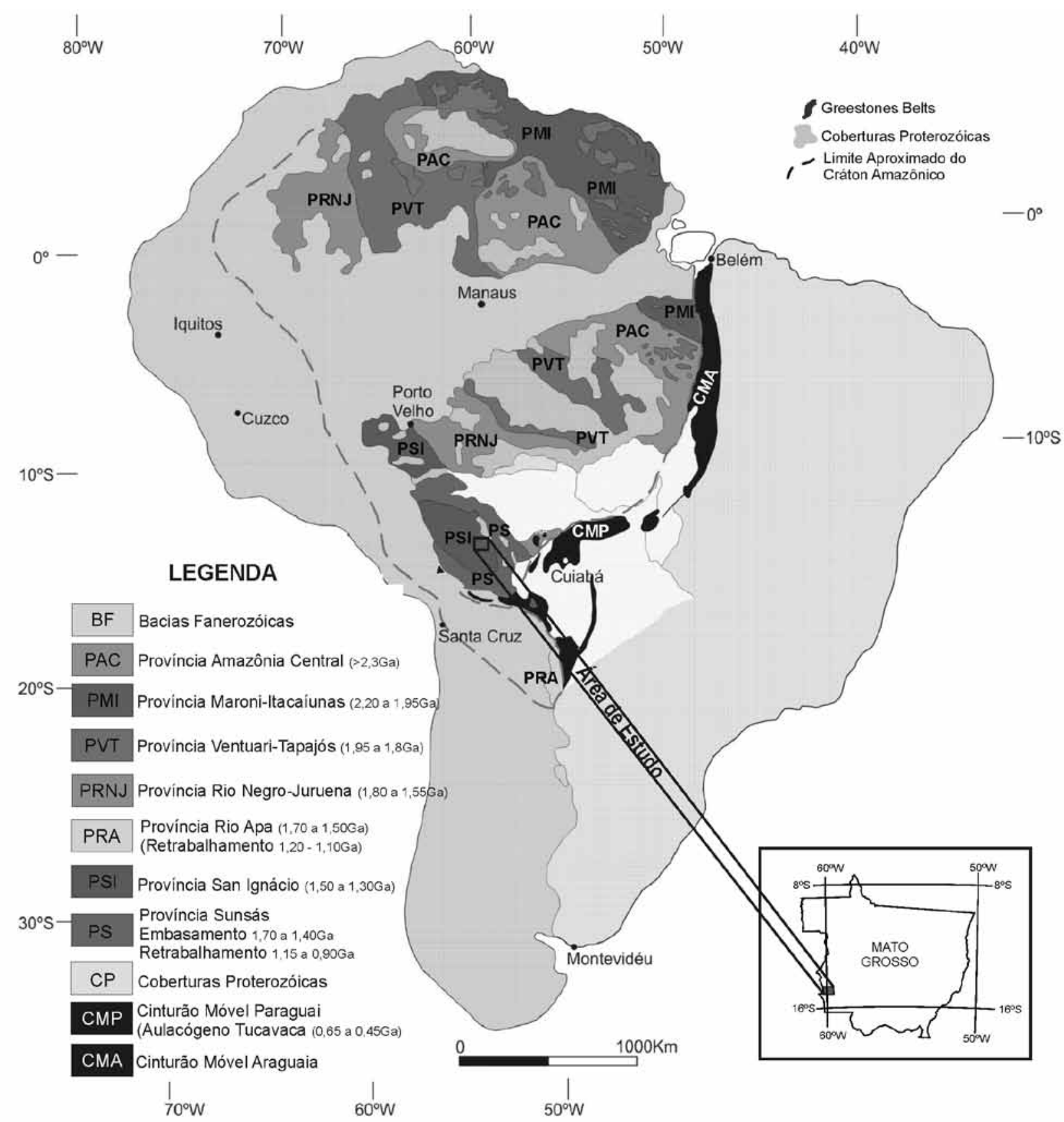

Figura 1 - Localização da área estudada no mapa de compartimentação geocronológica e tectônica do cráton Amazônico, considerando o Maciço Rio Apa como seu extremo meridional (Ruiz 2005). 
Petrologia e geocronologia (U/Pb-Sm/Nd) do Granito Passagem, Complexo Granitóide Pensamiento, SW do Cráton Amazônico, Mato Grosso

Tabela 1 - Compartimentação adotada neste trabalho a partir de Ruiz (2009) e equivalência com as propostas tectônicas anteriores.

\begin{tabular}{c|c|c|c}
\hline & TERRENO JAURU & TERRENO RIO ALEGRE & TERRENO PARAGUÁ \\
\hline Saes e Fragoso César (1996) & Terreno Jauru & Zona de Sutura & Terrenos Paraguá e San Pablo \\
\hline Saes (1999) & Terrenos Jauru e Santa Helena & Terreno Rio Alegre & Terreno Paraguá \\
\hline Geraldes et al. (2001) & $\begin{array}{c}\text { Terreno Alto Jauru e Batólito Santa } \\
\text { Helena }\end{array}$ & Domínio Rio Alegre & Domínio Rio Alegre \\
\hline Ruiz (2005) & Domínios Cachoeirinha e Jauru & Paraguá \\
\hline Ruiz (2009) & Terreno Jauru & Terreno Rio Alegre & Terreno Paraguá \\
\hline
\end{tabular}

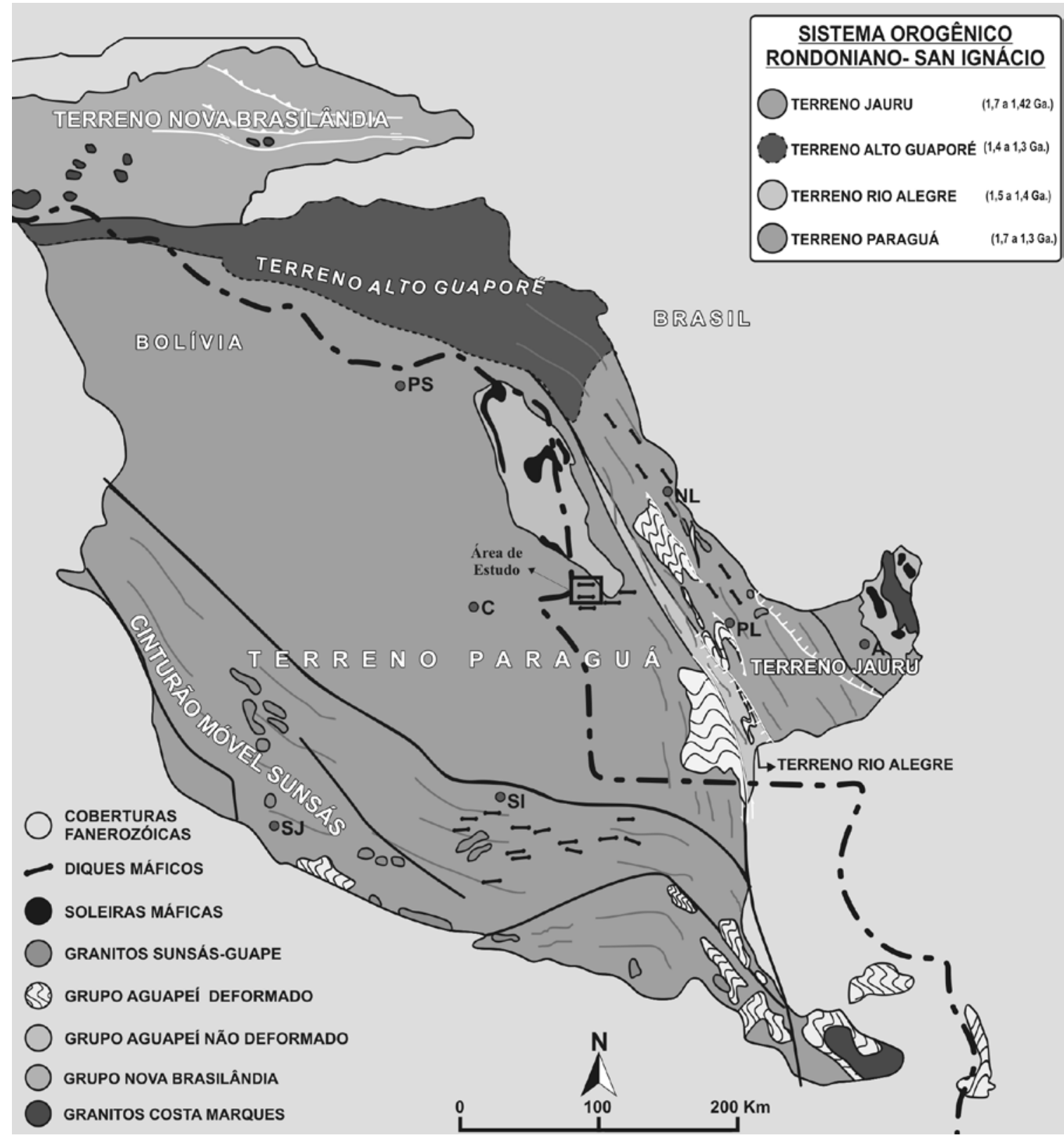

Figura 2 - Localização da área estudada no Mapa Tectônico do SW do cráton Amazônico em Mato Grosso, Rondônia e oriente da Bolívia (Ruiz 2009). 
bordas dessa última. Neste terreno são reconhecidas duas orogêneses que precederam a orogenia Sunsás: orogenia Lomas Manechis (1.74 a $1.69 \mathrm{Ga}$ ) e orogenia San Ignácio (1.35 a $1.3 \mathrm{Ga}$; Boger et al. 2005, Ruiz 2005, Santos et al. 2008). Esta última manifesta-se em todo o Terreno Paraguá, sendo caracterizada por deformação penetrativa, com trend estrutural NNW, metamorfismo de fácies xisto-verde a anfibolito e expressivo magmatismo ácidointermediário, de caráter sin a tardi cinemático.

Na região da Serra de Santa Bárbara, a orogenia San Ignácio é marcada pelo retrabalhamento tectônico-metamórfico do embasamento paleo-mesoproterozóico (gnaisses Chiquitania, granulitos Lomas Manechis e Grupo San Ignácio) e pela geração de batólitos e plútons graníticos orientados segundo o trend NNW. A granitogênese relacionada à orogenia San Ignácio é caracterizada pelo ortognaisse Tarumã $(1.38 \mathrm{Ga})$, sin-cinemático, fortemente foliado, colocado no pico orogênico $(1.38 \mathrm{Ga})$ e granito Lajes $(1.31 \mathrm{Ga})$, tarde cinemático, fracamente deformado, ambos com assinatura isotópica indicando fusão crustal associada à orogênese.

Na região de Vila Bela da Santíssima Trindade, na Serra Ricardo Franco onde se localiza a área estudada, são reconhecidos os mesmos registros das orogenias Lomas Manechis e San Ignácio (Ruiz 2009), entretanto não se verificam os efeitos tectônicos e metamórficos da orogenia Sunsás.

O Complexo granitóide Pensamiento (Litherland \& Klinck inédito, Litherland et al. 1986) forma grande parte do Terreno Paraguá, sendo o principal produto magmático relacionado à orogenia San Ignácio (Ruiz 2009, Matos et al. 2009, Bettencourt et al. 2010). Considerando o evento deformacional/metamórfico regional $\mathrm{D}_{3}$, desta orogenia, Litherland et al. (1986) agruparam as rochas deste complexo em dois principais grupos: i) granitos sin a tardi cinemáticos e ii) granitos tardi a pós cinemáticos.

Os granitóides sin a tardi cinemáticos são formados principalmente por hornblenda biotita monzogranitos e granodioritos, foliados, inequigranulares de granulação grossa a porfirítico, com idades U-Pb SHRIMP entre 1373 a 1347 Ma, destacando-se o La Junta, Florida, Puerto Alegre e Campamento. Os granitóides tardi a pós cinemáticos, pós-datam o evento deformacional $\mathrm{D}_{3}$ de Litherland et al. (1986), são constituídos por monzogranitos a granodioritos, isotrópi$\cos$, de granulação fina a porfirítica, exibindo contatos abruptos com as encaixates, destacando-se os granitos Diamantina (U-Pb SHRIMP $1340 \mathrm{Ma}$ ), Porvenir, Padre Eterno, Orobayaya, El Tigre e o Granófiro Piso Firme (Bettencourt et al. 2010).

Como continuidade desta atividade magmática descrita na Bolívia encontram-se em território brasileiro alguns corpos dos quais o granito Passagem corresponde ao alvo desta pesquisa.

Geologia e PeTrografia O granito Passagem ocorre como três corpos sub-circulares a elípticos (stocks) perfazendo uma área de aproximadamente 30 $\mathrm{km}^{2}$, bem como, em dezenas de outros menores, plugs e diques, alojados em rochas do granito Guaporeí e gnaisse Shangri-lá (Fig. 3). Seus contatos são tipicamente intrusivos que, no caso dos diques, mostram-se abruptos, retos e sem bordas de alteração, sendo comum tanto nos plugs como nos stocks a ocorrência de xenólitos de anfibolitos do Complexo Metamórfico San Ignácio, de ortognaisses Shangri-lá e de granitos foliados granito Guaporeí (Fig. 4). Seus litotipos afloram em blocos e matacões com cores entre cinza-escuro até branco e granulação de fina a média sendo em geral isotrópicos ou discretamente foliados (Fig. 4). Composicionalmente, são classificados como monzo a sienogranitos e, mais raramente granodioritos (Fig. 5), tendo biotita como único máfico primário essencial, que perfaz de 25 a menos de $5 \%$ do seu conteúdo modal, neste último caso caracterizando granitos hololeucocráticos.

As rochas do granito Passagem apresentam em geral textura equigranular hipidiomórfica (Fig. 6A) a inequigranular xenomórfica (Figs. $6 \mathrm{D}$ e $\mathrm{E}$ ), às vezes intergranular. Em algumas amostras de monzogranito e granodiorito as ripas de plagioclásio se unem formando uma trama onde os interstícios são preenchidos por um ou mais grãos de quartzo, feldspato alcalino e palhetas de biotita, caracterizando textura intergranular.

Microclina e ortoclásio são encontrados em cristais subédricos e grãos anédricos, com geminações, respectivamente, em grade e Carlsbad, apresentando textura pertítica em geral do tipo drops, mas também em stringer (Figs. $6 \mathrm{D}$ e E). Ocorrem, às vezes, truncados evidenciando deformação rúptil e exibem-se com bordas recristalizadas em minúsculos grãos de plagioclásio, mirmequita e quartzo (Figs. $6 \mathrm{D}$ e E). Alteramse comumente para sericita e argilo-minerais, mas mostram-se mais límpidos do que o plagioclásio. Por vezes, uma segunda geração de microclina, provavelmente produto de deformação, é reconhecida na matriz em grãos minúsculos geminados, não pertíticos e inalterados. O plagioclásio, classificado como albita ou oligoclásio através do método estatístico de Michel-Levy, apresenta-se em geral em cristais subédricos, de hábito tabular, com geminações polissintéticas do tipo albita ou periclina e, por vezes Carlsbad; sendo comum zonação normal, onde a parte cálcica altera-se mais intensamente (Figs. 6 A e B). Também pode ser encontrado em grãos neo-formados, muitas vezes com intercrescimento mirmequítico (Fig. 6 E). Identificam-se ainda argilização e saussuritização com neo-formação de epidoto/clinozoizita, sericita e calcita, mais pronunciados nos cristais que constituem a fase hóspede da textura pertítica ou nas porções mais cálcicas dos cristais zonados (Figs. 6 A, D e E). O quartzo apresenta-se em grãos anédricos intersticiais, às vezes com extinção ondulante, lamelas e bandas de deformação ou como ribbons e ainda em minúsculos grãos recristalizados nas margens de porfiroclastos definindo microestrutura em moldura, aspectos decorrentes de atuação de processos tardios de deformação intracristalina; observa-se também com hábito vermicular intercrescido com o plagioclásio (Fig. 6 E). A biotita ocorre em lamelas e palhetas isoladas de pleocroísmo castanho- 


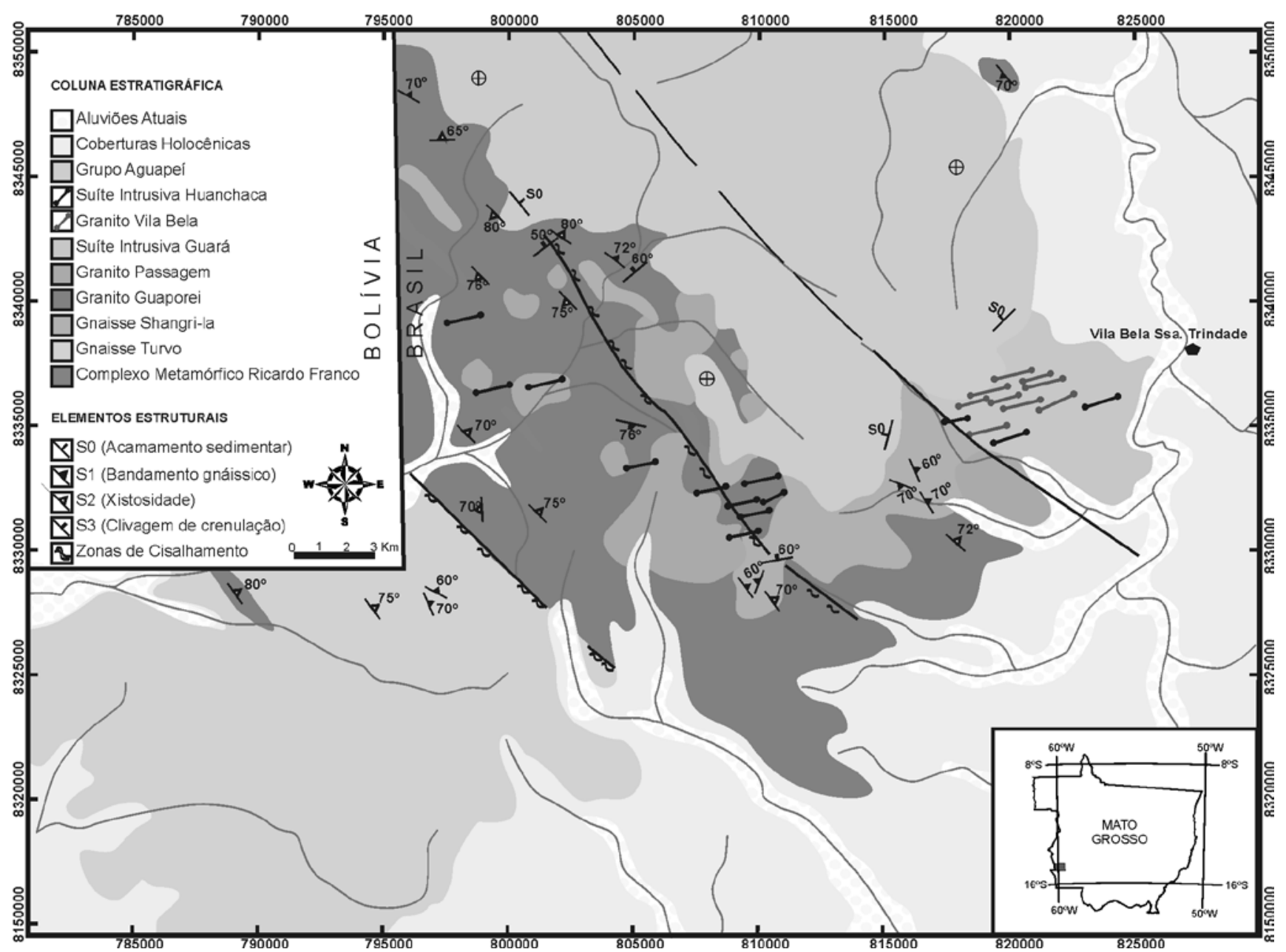

Figura 3 - Mapa geológico da região de Vila Bela (extraído de Ruiz et al. 2009) integrado das folhas Casalvasco e Ricardo Franco, Região de Vila Bela da Santíssima Trindade-MT.

claro a marrom-escuro (Figs. 6 A e B), com inclusões de zircão que nela desenvolve halos pleocróicos; pode ser encontrada parcial a totalmente alterada para clorita ou muscovita, às vezes, constituindo agregados que se dispõem com discreta orientação (Fig. 6 C). A titanita é um acessório comum, podendo representar fase primária em cristais romboédricos, ou secundária em grãos anédricos associados à biotita ou aos opacos. Estes últimos (óxidos de $\mathrm{Fe}$ e $\mathrm{Fe}+\mathrm{Ti}$ ) também são primários ou de alteração e ocorrem dispersos em cristais subédricos, com hábito cúbico ou em grãos anédricos, por vezes parcialmente desopacitizados, produzindo biotita e/ou clorita. A allanita é comum exibindo-se, em alguns exemplares, metamictizada com textura coronítica formada por epidoto e clorita. Apatita e zircão que ocorrem em grãos minúsculos dispersos na matriz ou inclusos nos feldspatos e biotita, também representam minerais primários; enquanto as fases de alteração correspondem, principalmente, à muscovita, sericita, epidoto/clinozoizita, argilo-minerais, rara calcita e clorita. O leucoxênio, produto de alteração da ilmenita, é identificado em agregados de cristais tabulares minúsculos, associados à titanita. A prehnita, proveniente de alteração hidrotermal, é encontrada em algu- mas amostras substituindo feldspatos, formando arranjo de cristais radiados, às vezes com estrutura bow-tie.

Algumas evidências observadas, tais como, geminação em grade (geminações combinadas albita+periclina) encontrada na microclina secundária, as formas de ocorrência do quartzo, bem como, a presença de intercrescimento simplectítico de quartzo vermicular em plagioclásio sódico substituindo microclina indicam atuação de processos de deformação no estado sólido.

As alterações tardias dos feldspatos alcalinos são evidenciadas essencialmente por sericitização, localmente responsável pela formação de muscovita secundária, enquanto que no plagioclásio este processo é geralmente acompanhado por saussuritização, resultando numa paragênese secundária com sericita (eventualmente muscovita) + epidoto microgranular \pm carbonato. Outras transformações pós-magmáticas observadas incluem cloritização da biotita e geração de titanita secundária formando corona em opacos.

GEOQUÍMICA O tratamento geoquímico do granito Passagem foi feito a partir das análises de oito amostras que mais o representam, obtidas no Laboratório Acme- 

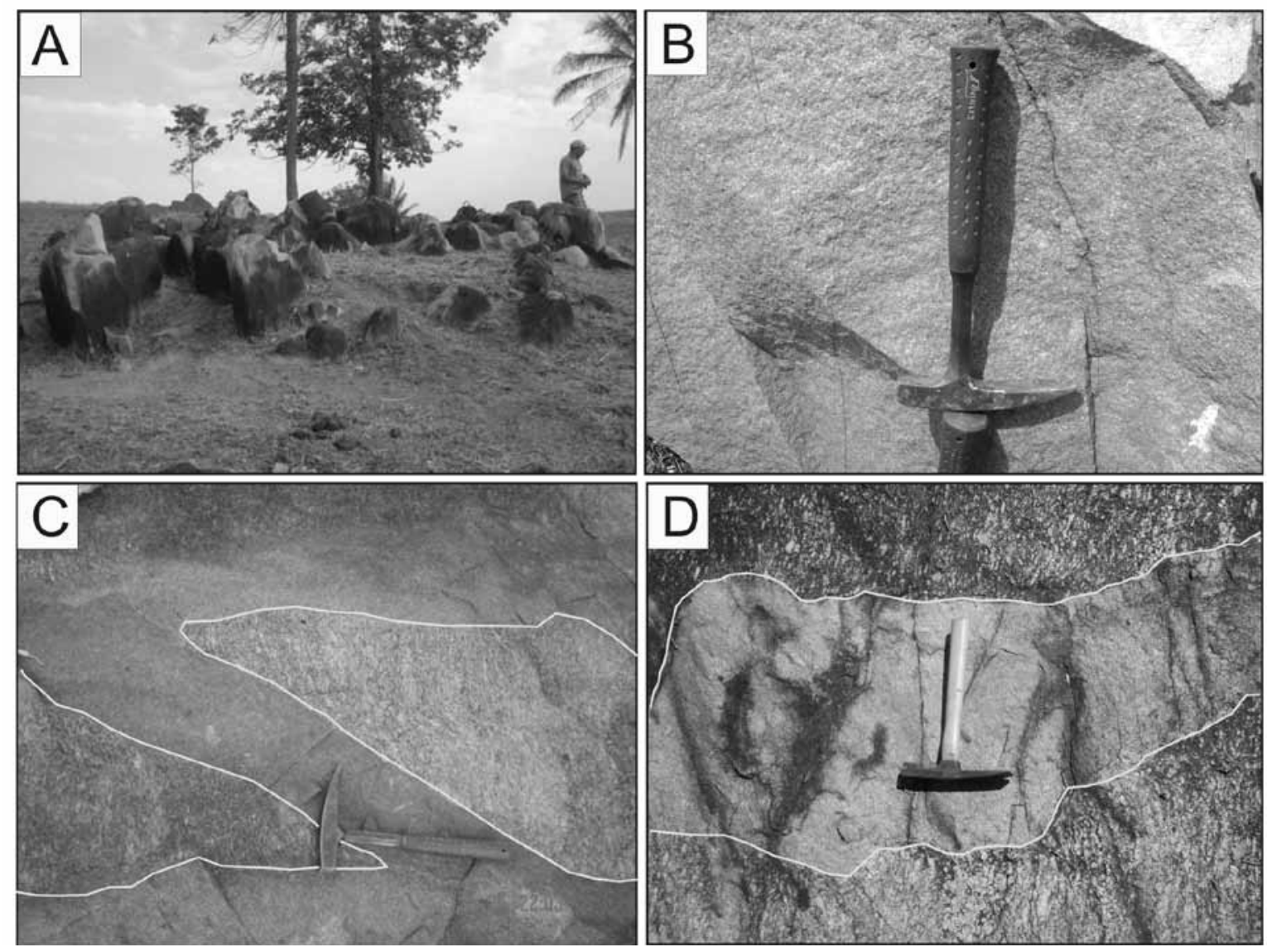

Figura 4 - Ilustrações do granito Passagem: A) forma de ocorrência em blocos; B) aspecto macroscópico - maciço, equigranular fino, cinza; C) com xenólitos do granito Guaporeí; D) como dique cortando o granito Guaporeí.

lab, Vancouver- Canadá, por ICP-MS e ICP-ES, para elementos maiores, menores e traços (ETR inclusive, Tab. 2). O comportamento dos elementos maiores, bem como do $\mathrm{V}, \mathrm{Zr}$, Sr e Ba, pode ser visualizado nos diagramas de Harker (Figs. 7 e 8), onde os teores de sílica, entre 67.52 e $71.62 \%$, caracterizam uma seqüência ácida pouco expandida, mas refletem tendências de variações coerentes, indicando uma evolução contínua marcada por cristalização fracionada para as rochas estudadas. Correlações lineares negativas com a sílica são observadas para $\mathrm{Al}_{2} \mathrm{O}_{3}, \mathrm{Fe}_{2} \mathrm{O}_{3}, \mathrm{CaO}, \mathrm{MgO}, \mathrm{TiO}_{2}, \mathrm{P}_{2} \mathrm{O}_{5}, \mathrm{~V}, \mathrm{Zr}, \mathrm{Sr}$ e Ba que estão ligadas ao empobrecimento progressivo, durante a diferenciação, em plagioclásio cálcico e em minerais máficos primários, tais como biotita, titanita, óxidos de $\mathrm{Fe}$ e $\mathrm{Fe}+\mathrm{Ti}$, apatita e zircão. Além de uma evolução por cristalização fracionada, mecanismo envolvendo assimilação de material crustal é evidenciado por razões $\mathrm{Rb} / \mathrm{Ba}$ baixas, variando entre 0,10 e 0,28 (Tab. 2). Os gráficos que envolvem os álcalis $\left(\mathrm{Na}_{2} \mathrm{O}\right.$ e $\mathrm{K}_{2} \mathrm{O}$ ) não mostram um padrão definido, com relativa dispersão resultante da maior mobilidade destes elementos durante a atuação de processos pós-magmáticos.

Utilizando-se o diagrama proposto por Cattalani \& Bambic (inédito) de discriminação de processos de alteração a partir de dados de elementos considerados como menos móveis em processos pós magmáticos

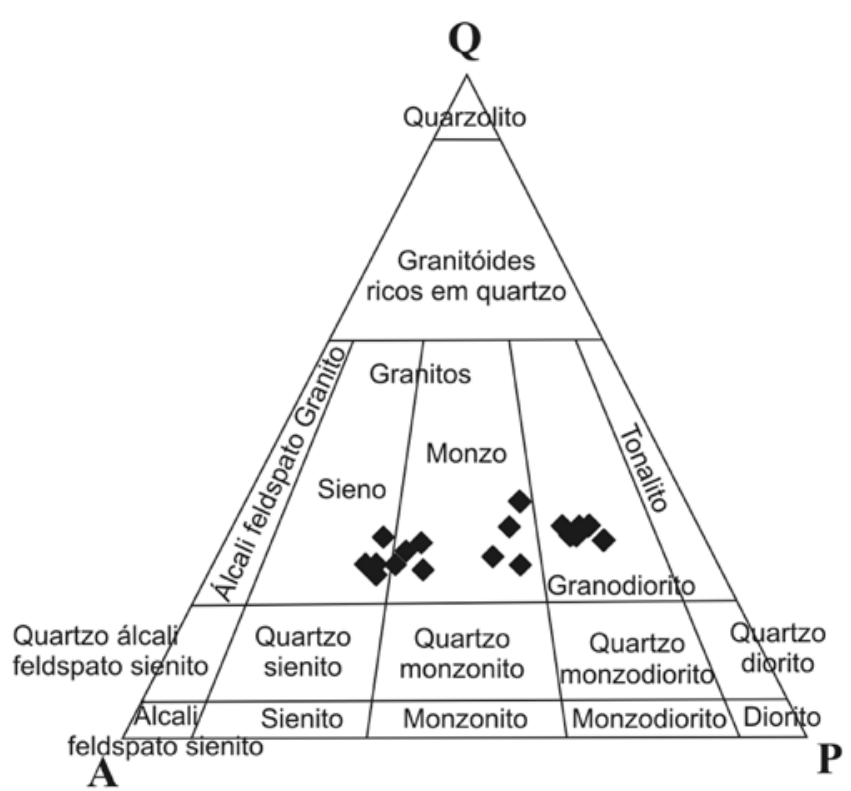

Figura 5 - Diagrama classificatório QAP para as rochas do granito Passagem.

$\mathrm{Al}_{2} \mathrm{O}_{3}$ versus $\mathrm{TiO}_{2}$ (Fig. 9A), os pontos que correspondem às rochas estudadas coincidem com composições 

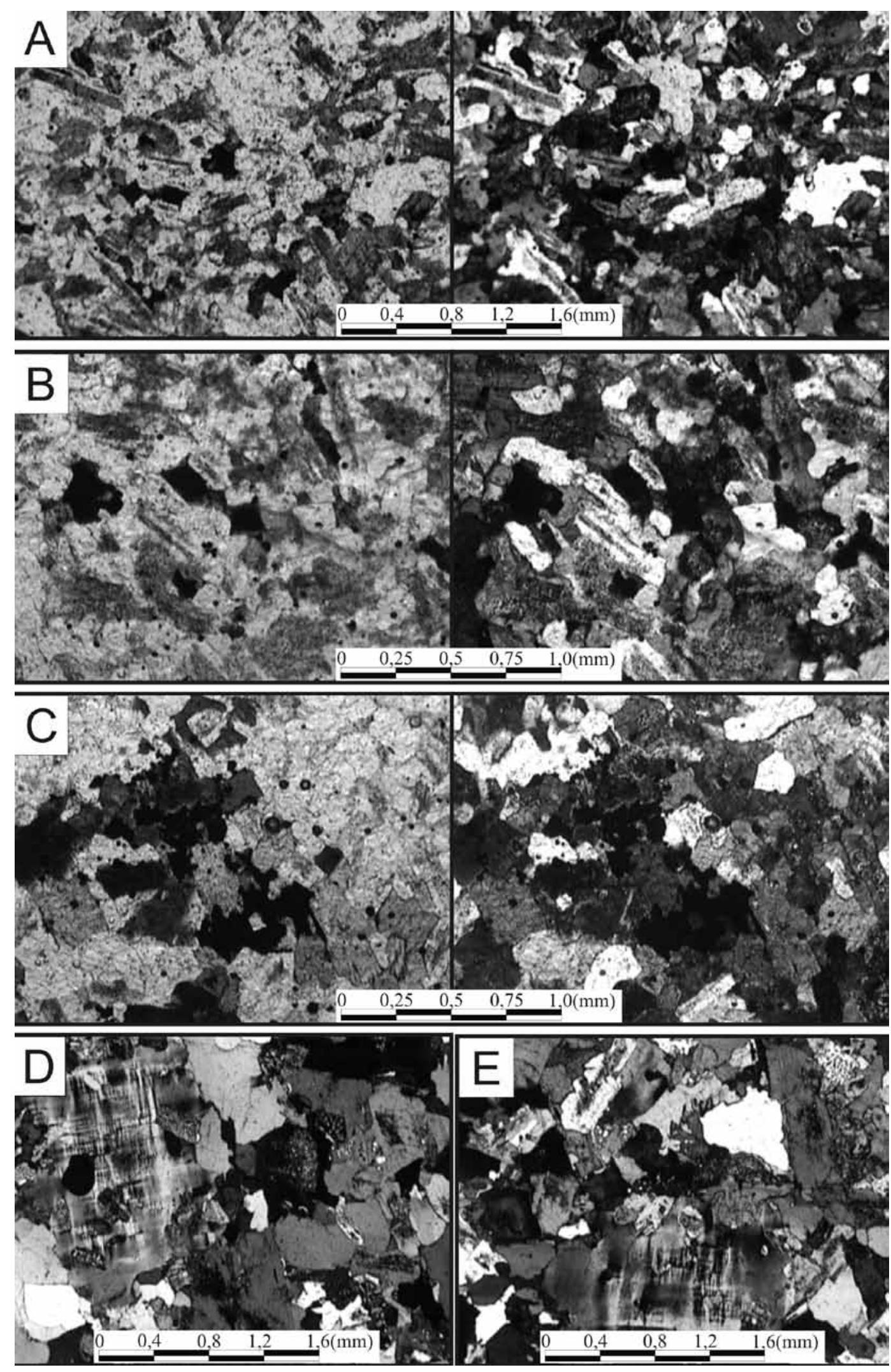

Figura 6 - Fotomicrografias do granito Passagem ilustrando: (A) Textura equigranular hipidiomórfica com ripas de plagioclásio zonado discretamente orientadas e raras palhetas de biotita, por vezes, cloritizada; (B) Plagioclásio em cristais subédricos de hábito tabular a anédrico, por vezes com zonação normal, onde a parte cálcica altera-se mais intensamente; (C) Concentração de cristais subédricos de biotita e opacos; (D) textura inequigranular xenomórfica com grão de microclina pertítica do tipo drops; (E) textura inequigranular xenomórfica, intercrescimentos pertíticos e mirmequiticos. Polarizadores paralelos à esquerda e cruzados à direita em (A), (B) e (C) e cruzados em (D) e (E). 



Figura 7 - Diagramas de Harker (elementos maiores, expressos em óxidos) para rochas do granito Passagem.

entre dacítica e riolítica posicionados próximos ao trend de fracionamento, sugerindo estágio de alteração incipiente em relação a estes elementos. Quando considerado total de álcalis versus sílica (Le Maitre 1989; Fig.9B) as rochas do granito Passagem coincidem com o domínio dos dacitos e riolitos; e classificam-se desde granodioritos até sienogranitos no diagrama $\mathrm{R}_{1}-\mathrm{R}_{2}$ (La Roche 1980; Fig.9C) que utiliza todos os elementos maiores. De forma semelhante, plotam-se no campo dos dacitos-riolitos, naqueles propostos por Winchester 

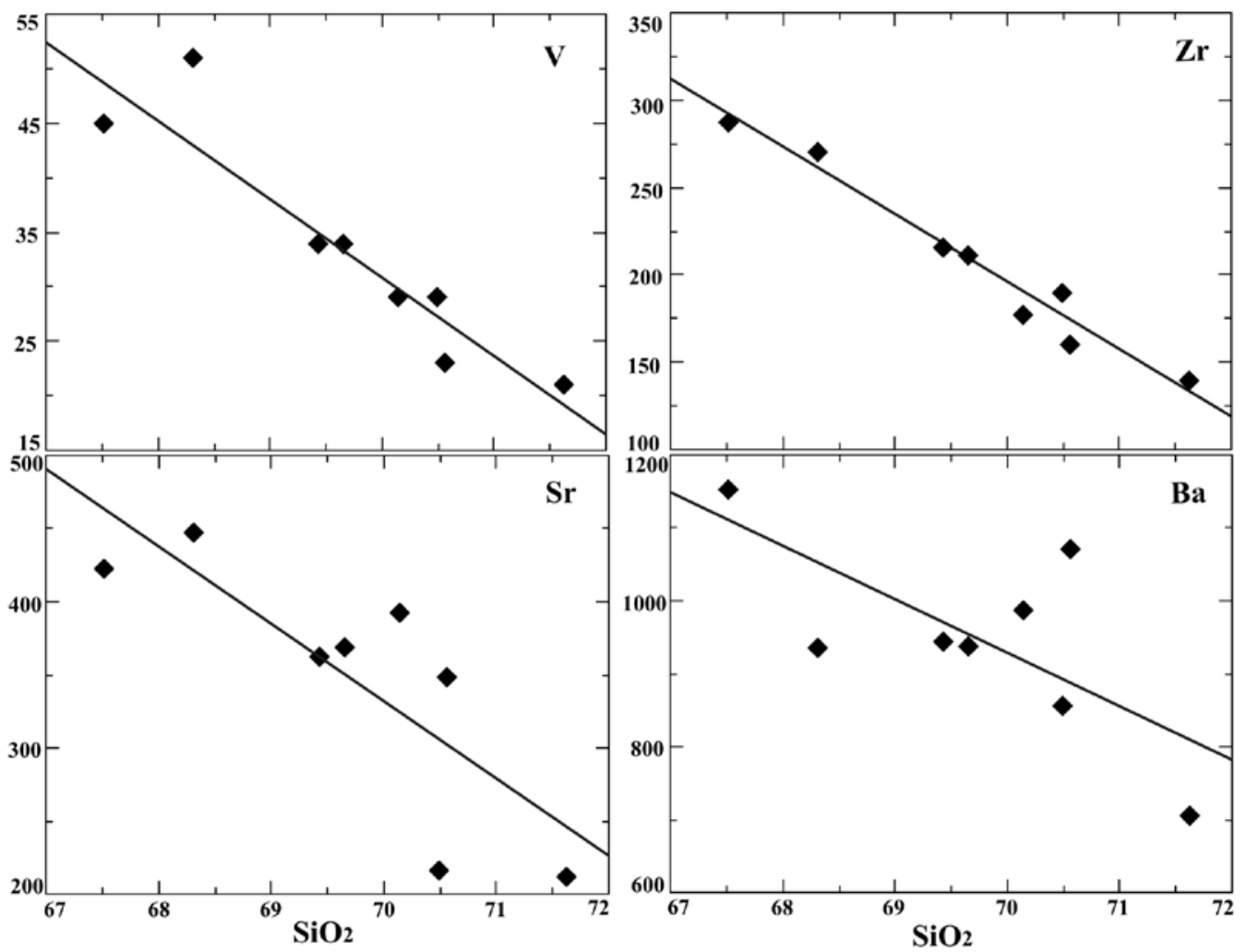

Figura 8 - Diagramas de Harker (elementos traços, expressos em ppm) para rochas do granito Passagem.

\& Floyd (1977) que utilizam, além de $\mathrm{SiO}_{2}$, elementos considerados menos móveis nos processos pós-magmáticos, tais como as razões $\mathrm{Zr} / \mathrm{TiO}_{2}$ e Nb/Y (Figs. 9D e 9E). O magmatismo que originou as rochas do granito Passagem é classificado como subalcalino do tipo cálcio-alcalino, como ilustrado nos diagramas propostos por Irvine \& Baragar (1971), respectivamente, álcalis versus $\mathrm{SiO}_{2}$ (Fig. 10A) e AFM (Fig. 10B). Neste último, observa-se também que os pontos que representam estes litotipos descrevem uma tendência aproximadamente linear que evolui em direção ao vértice dos álcalis, para valores muito baixos e decrescentes de $\mathrm{MgO}$. Seu caráter cálcio-alcalino é corroborado pela interseção dos trends do total álcalis e $\mathrm{CaO}$ versus $\mathrm{SiO}_{2}$ no diagrama de Peacock (1931; Fig. 10C) e no proposto por Barret \& MacLean (1999) que considera elementos traços menos móveis e ilustra que as rochas estudadas têm razões $\mathrm{Zr} / \mathrm{Y}$ geralmente maiores do que sete (Fig. 10D). A natureza cálcio-alcalina de alto $\mathrm{K}$ é ilustrada na figura $10 \mathrm{E}\left(\mathrm{K}_{2} \mathrm{O}\right.$ versus $\mathrm{SiO}_{2}$, Le Maitre 1989) enquanto que o diagrama total de álcalis versus sílica, proposto por Midlemost (1991; Fig. 10F), indica que as rochas mais evoluídas do granito Passagem pertencem à série silicática. Quanto à saturação em alumina, esse magma classifica-se como levemente peraluminoso no diagrama $\mathrm{A} / \mathrm{NK}$ e $\mathrm{A} / \mathrm{CNK}$ de Maniar \& Piccoli (1989; Fig. 10G); formado a uma temperatura de colocação por volta de $900^{\circ} \mathrm{C}$ sugerida pela disposição desses pontos próxima à curva de saturação da apatita no diagrama $\mathrm{P}_{2} \mathrm{O}_{5}$ versus $\mathrm{SiO}_{2}$ proposto por Watson \& Harrison (1984; Fig. 10H).

As concentrações e razões dos elementos terras raras do granito Passagem são apresentadas na tabela 2. Os padrões definidos por esses elementos, normalizados pelos valores condríticos de Nakamura (1977; Fig. 11A) apresentam enriquecimento dos elementos terras raras leves ( $\mathrm{La}, \mathrm{Ce}, \mathrm{Pr}, \mathrm{Nd}$ e $\mathrm{Sm}$ ) em relação aos elementos terras raras pesados (Dy, Ho, Er, Tm, Yb e Lu), com razões La/ $\mathrm{Yb}_{(\mathrm{n})}$ entre 9 e 21 e configuração semelhante à apresentada por magmas cálcio-alcalinos, exibindo, em geral, uma disposição sub-horizontalizada para os últimos, bem como, moderadas a pronunciadas anomalias negativas de $\mathrm{Eu}\left(\mathrm{Eu} / \mathrm{Eu}^{*}\right.$ entre 0.4 e 0.7$)$ o que sugere diferenciação com maior fracionamento de plagioclásio. Alguns elementos traços além de $\mathrm{K}_{2} \mathrm{O}$ normalizados contra os valores dos granitos de Cordilheira Meso-Oceânica de Pearce et al. (1984) estão ilustrados na figura 11B. Os padrões evidenciam um enriquecimento dos elementos litófilos de íons grandes (LILE) $\mathrm{K}, \mathrm{Rb}, \mathrm{Ba}$ e Th em relação aos elementos de alta carga (HFSE) Nb, Ce, Hf, Zr, Sm, Y e Yb. No grupo dos LILE observa-se uma anomalia positiva de $\mathrm{Rb}$ em relação ao $\mathrm{K}_{2} \mathrm{O}$ e $\mathrm{Ba}$ que aparecem empobrecidos pelo fracionamento de biotita; e uma discreta anomalia positiva de Th assinalando contaminação crustal. No grupo dos HFSE notam-se baixos valores de $\mathrm{Ta}$ e $\mathrm{Nb}$, anomalia positiva de Ce e Sm em relação aos elementos adjacentes confirmando assimilação de crosta, e valores normalizados de $\mathrm{Y}$ e $\mathrm{Yb}$ inferiores a 1 sugerindo a presença de granada residual em sua fonte (Scheepers 1995). 
Tabela 2 - Composição química de elementos maiores, menores (\% em peso), traços e terras raras (ppm) de rochas do granito Passagem.

\begin{tabular}{|c|c|c|c|c|c|c|c|c|}
\hline Amostras & P1 & P2 & P3 & P4 & P5 & P6 & P7 & P8 \\
\hline \multicolumn{9}{|l|}{ Elementos } \\
\hline $\mathrm{SiO}_{2}$ & 71.62 & 70.49 & \begin{tabular}{|l|}
70.56 \\
\end{tabular} & 70.14 & 68.31 & 67.52 & \begin{tabular}{|l|}
69.66 \\
\end{tabular} & 69.43 \\
\hline $\mathrm{TiO}_{2}$ & 0.26 & 0.32 & 0.27 & 0.31 & 0.57 & 0.53 & 0.36 & 0.37 \\
\hline $\mathrm{Al}_{2} \mathrm{O}_{3}$ & $\begin{array}{ll}14.16 \\
\end{array}$ & 14.25 & \begin{tabular}{|l|}
14.91 \\
\end{tabular} & $\begin{array}{ll}14.87 \\
\end{array}$ & 15.06 & 15.56 & 15.23 & 15.24 \\
\hline $\mathrm{Fe}_{2} \mathrm{O}_{3}$ & 2.71 & 4.22 & 2.70 & 2.79 & 3.87 & 3.98 & 3.08 & 3.12 \\
\hline $\mathrm{MnO}$ & 0.05 & 0.05 & 0.03 & 0.03 & 0.05 & 0.04 & 0.03 & 0.03 \\
\hline $\mathrm{MgO}$ & 0.40 & 0.56 & 0.49 & 0.58 & 0.89 & 0.85 & 0.56 & 0.57 \\
\hline $\mathrm{CaO}$ & 1.25 & 1.88 & 1.86 & 2.14 & 2.42 & 2.41 & 1.97 & 2.07 \\
\hline $\mathrm{Na}_{2} \mathrm{O}$ & 4.03 & 3.52 & 4.21 & 4.21 & 4.27 & 3.87 & 4.19 & 4.17 \\
\hline $\mathrm{K}_{2} \mathrm{O}$ & 4.60 & 4.30 & 3.59 & 3.39 & 3.23 & 3.45 & 3.49 & 3.56 \\
\hline $\mathrm{P}_{2} \mathrm{O}_{5}$ & 0.04 & 0.08 & 0.07 & 0.09 & 0.14 & 0.18 & 0.09 & 0.10 \\
\hline LOI & 0.60 & 0.00 & 1.1 & 1.3 & 1.0 & 1.4 & 1.1 & 1.1 \\
\hline Total & 99.74 & 99.69 & \begin{tabular}{|l|l|}
99.80 \\
\end{tabular} & 99.80 & \begin{tabular}{|l|}
99.77 \\
\end{tabular} & 99.74 & \begin{tabular}{|l|}
99.80 \\
\end{tabular} & 99.80 \\
\hline $\mathrm{Sc}$ & 5 & 5 & 3 & 4 & 7 & 6 & 4 & 4 \\
\hline $\mathrm{Ba}$ & 705 & 855 & 1071 & 988 & 935 & 1152 & 938 & 945 \\
\hline $\mathrm{Be}$ & 3 & 3 & 2 & 2 & 2 & 1 & 2 & 1 \\
\hline Co & 94.9 & 64.5 & 3.1 & 4.3 & 6.2 & 5.6 & 3.8 & 4.7 \\
\hline $\mathrm{Cs}$ & 3.2 & 4 & 1.8 & 1.4 & 0.8 & 1.5 & 1.3 & 1.2 \\
\hline $\mathrm{Ga}$ & 18.9 & 20 & 20.8 & 20.7 & 21.5 & 21.1 & 22.1 & 21.7 \\
\hline $\mathrm{Hf}$ & 4.4 & 6.1 & 4.8 & 5.2 & 7.8 & 8 & 5.7 & 6.5 \\
\hline $\mathrm{Nb}$ & 11.2 & 18.2 & 6.4 & 5.9 & 8.9 & 9.3 & 6.8 & 6.5 \\
\hline $\mathrm{Rb}$ & 196.3 & 171.5 & \begin{tabular}{|l|}
105.6 \\
\end{tabular} & 103.7 & 96.1 & 153.8 & \begin{tabular}{|l|}
108.6 \\
\end{tabular} & 104.7 \\
\hline Sn & 3 & 42 & 1 & 1 & 2 & 2 & 2 & 2 \\
\hline $\mathrm{Sr}$ & 211.7 & 216 & \begin{tabular}{|l|}
348.4 \\
\end{tabular} & 392.3 & 447 & 422.2 & \begin{tabular}{|l|}
368.9 \\
\end{tabular} & 362 \\
\hline $\mathrm{Ta}$ & 1.3 & 1.9 & 0.7 & 0.5 & 0.5 & 0.5 & 0.4 & 0.4 \\
\hline Th & 14.4 & 17.7 & 8 & 8.3 & 9.5 & 12.1 & 8.8 & 9.6 \\
\hline $\mathrm{U}$ & 3.6 & 2.9 & 3.7 & 2.8 & 2.2 & 1.7 & 1.7 & 2.5 \\
\hline $\mathrm{V}$ & 21 & 29 & 23 & 29 & 51 & 45 & 34 & 34 \\
\hline $\mathrm{W}$ & 654.5 & 540 & 0.5 & 0.5 & 0.5 & 0.5 & 0.5 & 0.5 \\
\hline $\mathrm{Zr}$ & 139.6 & 189.5 & \begin{tabular}{|c|}
159.8 \\
\end{tabular} & 176.9 & \begin{tabular}{|l|}
270.1 \\
\end{tabular} & 287.5 & \begin{tabular}{|l|}
210.8 \\
\end{tabular} & 215.7 \\
\hline $\mathrm{Y}$ & 23.9 & 33.1 & 21.1 & 13.9 & 29.7 & 14 & 24.7 & 23.6 \\
\hline Mo & 3.8 & 13.8 & 0.2 & 0.3 & 0.3 & 0.3 & 0.4 & 0.3 \\
\hline $\mathrm{Cu}$ & 3.9 & 10.6 & 13.9 & 7.3 & 21.4 & 4 & 4 & 4.3 \\
\hline $\mathrm{Pb}$ & 23.2 & 6.7 & 5.6 & 5.4 & 5.9 & 7.9 & 4.4 & 3.8 \\
\hline $\mathrm{Zn}$ & 52 & 63 & 53 & 52 & 71 & 54 & 46 & 46 \\
\hline $\mathrm{Ni}$ & 20.9 & 49.1 & 20 & 20 & 20 & 20 & 20 & 20 \\
\hline As & 0.8 & 0.5 & 0.5 & 0.5 & 0.5 & 0.5 & 0.5 & 0.5 \\
\hline $\mathrm{Sb}$ & 0.1 & 0.1 & 0.1 & 0.1 & 0.1 & 0.1 & 0.1 & 0.1 \\
\hline $\mathrm{Bi}$ & 0.2 & 0.1 & 0.1 & 0.1 & 0.1 & 0.1 & 0.1 & 0.1 \\
\hline $\mathrm{Ag}$ & 0.1 & 0.1 & 0.1 & 0.1 & 0.1 & 0.1 & 0.1 & 0.1 \\
\hline $\mathrm{Au}$ & 4 & 6.5 & 0.5 & 0.5 & 0.5 & 0.5 & 1.5 & 0.5 \\
\hline $\mathrm{Tl}$ & 01 & 0.5 & 0.1 & 0.1 & 0.1 & 0.1 & 0.1 & 0.1 \\
\hline $\mathrm{La}$ & 31.3 & 41.6 & 26.9 & 28.4 & 39.7 & \begin{tabular}{|l|}
48.2 \\
\end{tabular} & \begin{tabular}{|l|}
35.9 \\
\end{tabular} & 34.3 \\
\hline $\mathrm{Ce}$ & \begin{tabular}{|l|}
63.8 \\
\end{tabular} & 93.4 & $\begin{array}{l}50.1 \\
\end{array}$ & 53.6 & 83.1 & 97.6 & 69.1 & 66.5 \\
\hline $\operatorname{Pr}$ & 7.98 & 11.64 & 5.88 & 6.18 & \begin{tabular}{|l|}
10.01 \\
\end{tabular} & 11.17 & \begin{tabular}{l|l|}
8.31 \\
\end{tabular} & 7.78 \\
\hline $\mathrm{Nd}$ & 30.3 & $\begin{array}{l}44.8 \\
\end{array}$ & 24.3 & 23.9 & 39.7 & \begin{tabular}{|l|}
41.5 \\
\end{tabular} & \begin{tabular}{|l|}
31.5 \\
\end{tabular} & 31.2 \\
\hline $\mathrm{Sm}$ & 5.99 & 8.68 & 4.06 & 3.87 & 7.16 & 6.01 & \begin{tabular}{l|}
5.57 \\
\end{tabular} & 5.34 \\
\hline $\mathrm{Eu}$ & 0.82 & 1.05 & 1 & 0.83 & 1.38 & 1.24 & 1.16 & 1.10 \\
\hline $\mathrm{Gd}$ & 5.41 & 7.33 & 4.13 & 3.19 & 6.07 & \begin{tabular}{|l|}
4.14 \\
\end{tabular} & \begin{tabular}{|l|}
5.03 \\
\end{tabular} & 4.88 \\
\hline $\mathrm{Tb}$ & 0.82 & 1.18 & 0.62 & 0.45 & 0.95 & 0.50 & 0.76 & 0.72 \\
\hline Dy & 4.35 & 6.02 & 3.45 & 2.34 & 5.11 & 2.40 & \begin{tabular}{|l|}
3.91 \\
\end{tabular} & 3.81 \\
\hline Ho & 0.80 & 1.11 & 0.68 & 0.47 & 1.03 & 0.47 & 0.82 & 0.75 \\
\hline $\mathrm{Er}$ & 2.31 & 3.16 & 1.97 & 1.33 & 3.04 & 1.39 & 2.30 & 2.22 \\
\hline $\mathrm{Tm}$ & 0.36 & 0.49 & 0.30 & 0.21 & 0.46 & 0.22 & 0.33 & 0.32 \\
\hline $\mathrm{Yb}$ & 2.25 & 2.98 & 1.84 & 1.22 & 2.89 & 1.50 & 2.02 & 1.96 \\
\hline $\mathrm{Lu}$ & 0.34 & 0.43 & 0.27 & 0.19 & 0.42 & 0.25 & 0.31 & 0.31 \\
\hline $\mathrm{Eu} / \mathrm{Eu}^{*}$ & 0.4 & 0.4 & 0.7 & 0.7 & 0.6 & 0.7 & 0.6 & 0.6 \\
\hline $\mathrm{La} / \mathrm{Yb}$ & 9.27 & 9.30 & 9.74 & 15.51 & 9.15 & 21.42 & 11.84 & 11.66 \\
\hline $\mathrm{Zr} / \mathrm{Y}$ & 5.84 & 5.73 & 7.57 & 12.7 & 9.09 & 20.5 & 8.53 & 9.14 \\
\hline $\mathrm{Rb} / \mathrm{Ba}$ & 0.28 & 0.20 & 0.10 & 0.10 & 0.10 & \begin{tabular}{|l|}
0.13 \\
\end{tabular} & \begin{tabular}{|l|}
0.12 \\
\end{tabular} & 0.11 \\
\hline
\end{tabular}

Os diagramas discriminantes de ambiente tectônico de Pearce et al. (1984) e Pearce (1996) Rb versus $\mathrm{Y}+\mathrm{Nb}$ (Fig. 12A), bem como, o proposto por Harris et al. (1986) Hf-Rb-Ta (Fig. 12B) indicam que as rochas do granito Passagem foram geradas em ambiente de arco magmático provavelmente em época pós-colisional.

GEOCRONOLOGIA O Terreno Paraguá é praticamente desconhecido do ponto de vista geocronológico, sendo que os dados disponíveis limitam-se aos apresentados por Litherland et al (1986), na Bolívia. Desta forma, o presente estudo contribui para o conhecimento isotópico do terreno Paraguá ao apresentar idades modelo ( $\mathrm{Sm}-\mathrm{Nd}$ em rocha total) e U-Pb em zircão (por LA-ICP-MS) do granito Passagem, que ocorre no território brasileiro.

\section{Determinações Geocronológicas U-Pb A amostra da-} tada corresponde a um sienogranito leucocrático, inequigranular médio a fino e de estrutura maciça, tendo sido coletada próxima ao Rio Passagem. Dos, aproximadamente, 50 grãos de zircão selecionados foram utilizados 23 para análise. Na lupa, estes se caracterizam por cristais pequenos, às vezes fraturados ou quebrados, amarelados e mistos, variando de transparentes a escuros.

As imagens de Microscopia Eletrônica de Varredura (MEV) precedem as análises e permitam a visualização interna do grão e, assim, a melhor escolha do local apropriado para sonda. Nas figuras $13 \mathrm{~A}, \mathrm{C}$ e E e $14 \mathrm{~A}$ a $\mathrm{G}$ observa-se que os cristais de zircão apresentam terminações piramidais, pequenas fraturas perpendiculares às faces, bem como discreta zonação (Figs. $14 \mathrm{C}$ e E). As figuras 13B, D e F indicam onde o feixe do laser incidiu no cristal - spots. Os dados analíticos com as razões isotópicas dos cristais datados estão na tabela 3. Esses resultados foram adquiridos no Laboratório de Geologia Isotópica na Universidade Federal do Rio Grande do Sul.

O Diagrama Concórdia (Fig. 15), gerado a partir das razões obtidas, mostra que os zircões analisados forneceram uma idade concordante de $1291 \pm 16 \mathrm{Ma}$ e uma do intercepto superior da concórdia de $1284 \pm 20$ Ma. A primeira deve corresponder à idade provável de alojamento do corpo, sendo a concordante (1284 \pm 20 Ma) a idade mínima de cristalização desse granito.

Determinações Geocronológicas Sm-Nd Os dados da tabela 4 mostram os valores obtidos de rocha total para a amostra do granito Passagem (P2), os quais indicam uma idade modelo $\mathrm{T}_{\mathrm{DM}}$ de $1.6 \mathrm{Ga} \mathrm{e}$ valor negativo de $\varepsilon \mathrm{Nd}(0)-10,56$. A idade $\mathrm{T}_{\mathrm{DM}}$ sugere que o protólito magmático sofreu o fracionamento mantélico por volta de $1600 \mathrm{Ma}$, durante o período Orosiriano, no Paleoproterozóico, enquanto o valor calculado negativo de $\quad \varepsilon_{\mathrm{Nd}(1,29 \mathrm{Ga})}$ em torno de -7 assinala uma natureza híbrida do magma parental, indicando contaminação crustal. Resultados adquiridos no laboratório de estudos geocronológicos, geodinâmicos e ambientais da Universidade Federal de Brasília. 

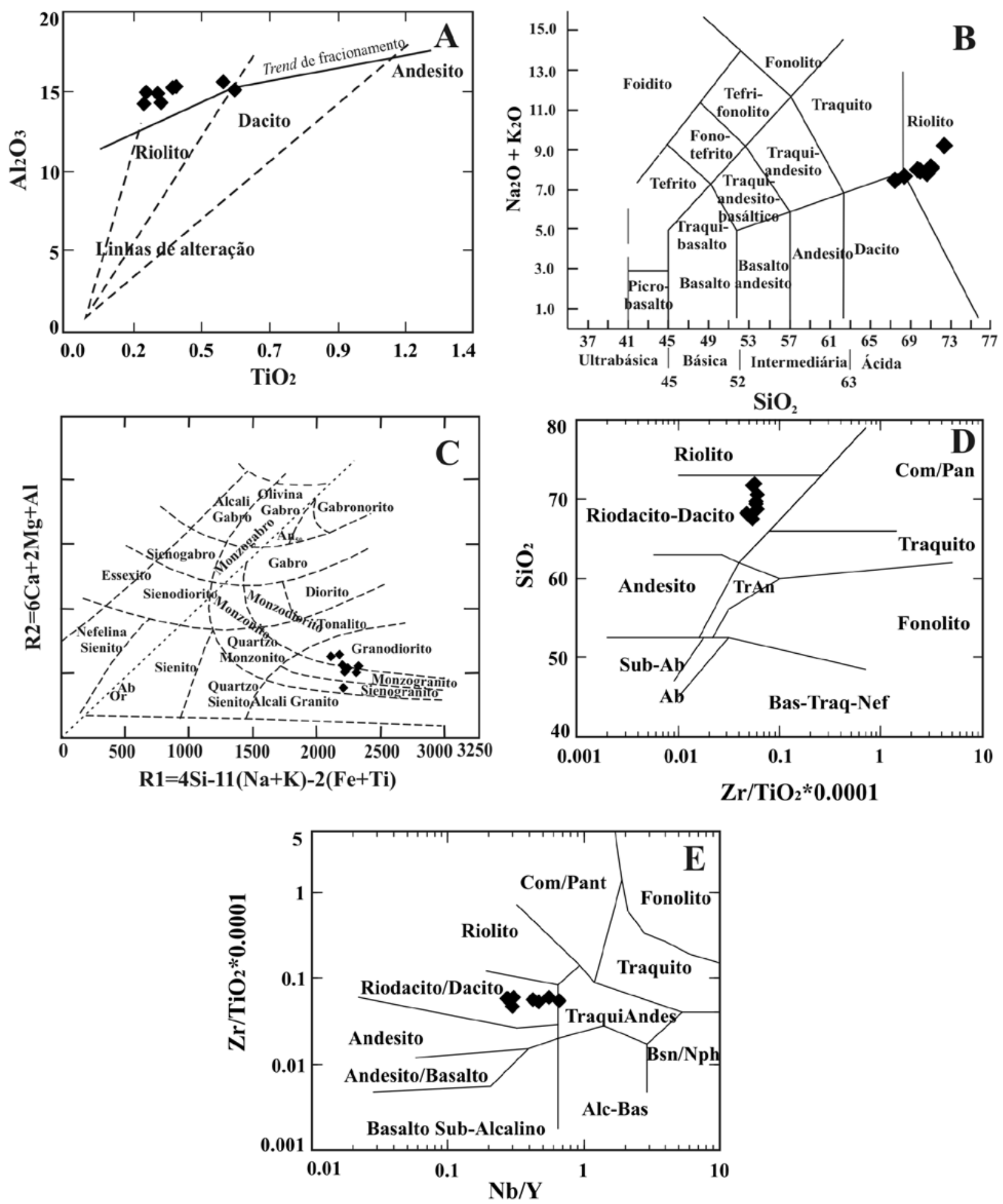

Figura 9 - Diagramas classificatórios para o granito Passagem: (A) $\mathrm{Al}_{2} \mathrm{O}_{3}$ versus $\mathrm{TiO}_{2}$ (Cattalani \& Bambic inédito); (B) álcalis versus sílica (Le Maitre 1989); (C) $R_{1}-R_{2}$ (La Roche 1980); (D) $\mathrm{SiO}_{2}$ versus $\mathrm{Zr} / \mathrm{TiO}_{2} e$ (E) $\mathrm{Zr} / \mathrm{TiO}{ }_{2}$ versus $\mathrm{Nb} / Y$ propostos por Winchester \& Floyd (1977).

CONSIDERAÇÕES FINAIS E CONCLUSÃO Na evolução geológica do SW do Cráton Amazônico o magmatismo ácido representado pelos stocks, plútons e diques do granito Passagem está inserido no contexto da Província Rondoniana-San Ignácio (1.56 a $1.3 \mathrm{Ga})$ de Bettencourt et al. (2010) e retrata importante evento magmático registrado no Terreno Paraguá (Ruiz 2009), durante o de- senvolvimento da Orogenia San Ignácio (1.37 a $1.3 \mathrm{Ga})$.

$\mathrm{O}$ granito Passagem consiste de monzo a sienogranitos e, mais raramente granodioritos que têm biotita como único máfico primário essencial e textura preferencialmente equigranular hipidiomórfica a inequigranular xenomórfica, às vezes intergranular, fina a média. De acordo com os feldspatos alcalinos, estas rochas classificam-se como granitos 



Figura 10 - Diagramas geoquímicos para o granito Passagem: (A) Total de álcalis versus sílica e (B) AFM (Irvine \& Baragar 1971); (C) Total de álcalis versus sílica (Peacock 1931); (D) Zr versus Y (Barret \& MacLean 1999); (E) Ko versus $\mathrm{SiO}$, (Le Maitre 1989); (F)Total de álcalis versus sílica (Middlemost 1991); (G) A/NK versus A/CNK (Maniar \& Piccoli 1989) e (H) $\mathrm{P}_{2} \mathrm{O}_{5}$ versus $\mathrm{SiO}_{2}$ (Watson \& Harrison 1984). 

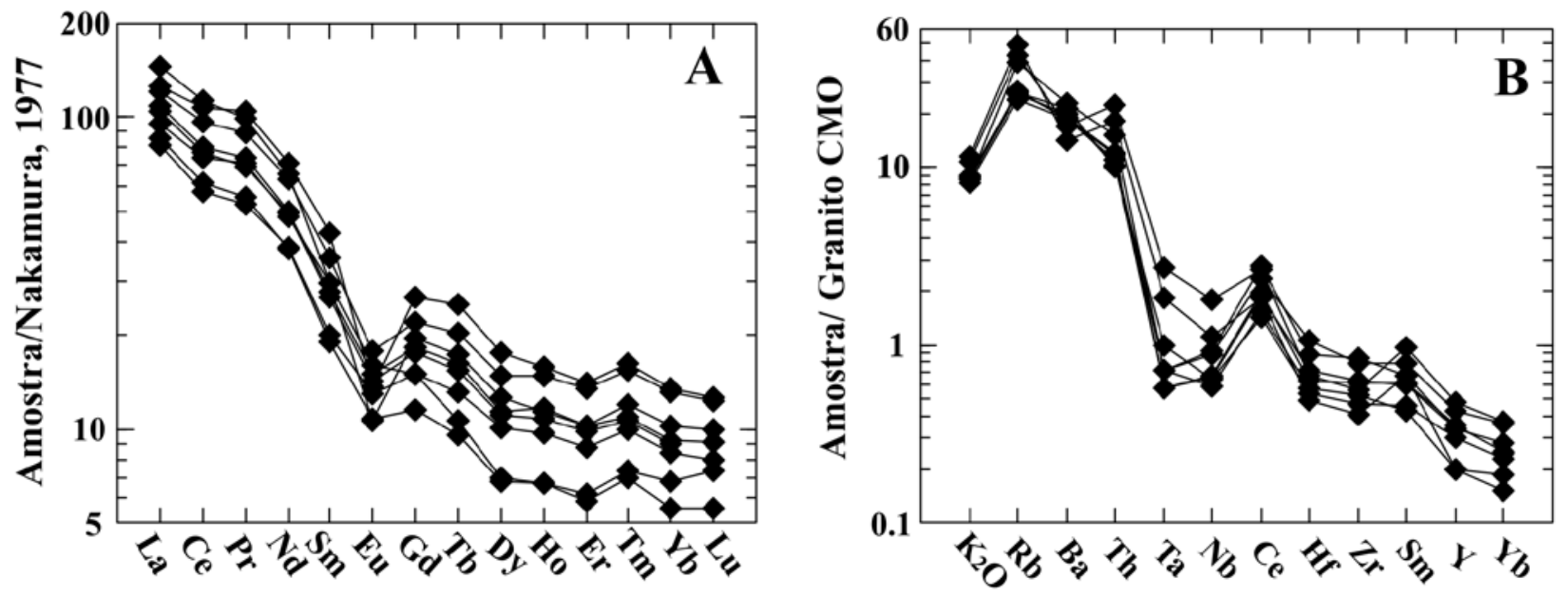

Figura 11 - Padrões de distribuição do granito Passagem nos diagramas de: (A) ETR, normalizados pelos valores condriticos de Nakamura (1977); (B) Elementos traços, normalizados pelos valores dos granitos de Cordilheira Meso-Oceânica de Pearce et al. (1984).
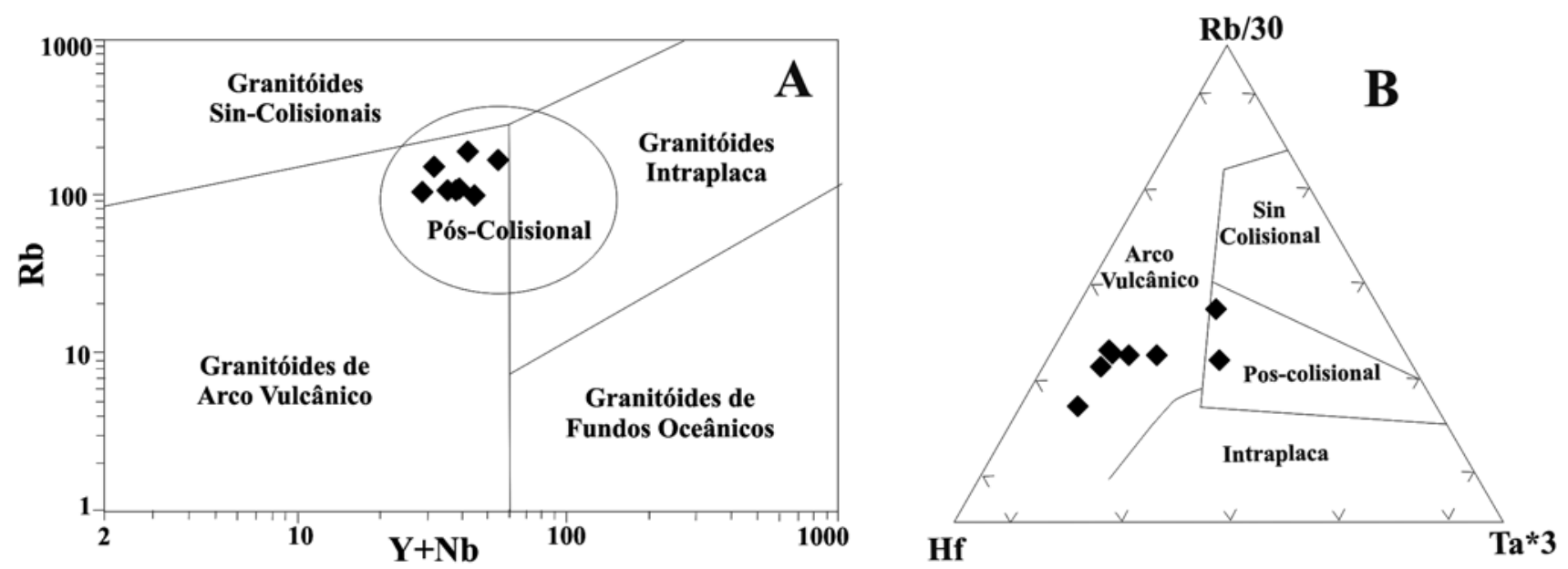

Figura 12 - Diagramas de classificação tectônica para o granito Passagem: (A) Rb versus $Y+N b$ (Pearce et al. 1984, Pearce 1996); (B) Hf-Rb/30-Ta*3 (Harris et al. 1986).

Tabela 3 - Dados Geocronológicos e razões isotópicas U-Pb da amostra P2 do granito Passagem.

\begin{tabular}{|c|c|c|c|c|c|c|c|c|c|c|}
\hline \multirow[t]{2}{*}{$\mathrm{N}^{\circ}$ Spot } & \multicolumn{5}{|c|}{ Concórdia 1} & \multicolumn{5}{|c|}{ Concórdia 2} \\
\hline & ${ }^{207} \mathrm{~Pb} /{ }^{235} \mathrm{U}$ & \pm & ${ }^{206} \mathrm{~Pb} /{ }^{238} \mathrm{U}$ & \pm & Rho & ${ }^{238} \mathrm{U} /{ }^{206} \mathrm{~Pb}$ & \pm & ${ }^{207} \mathrm{~Pb} /{ }^{206} \mathrm{U}$ & \pm & Rho \\
\hline Zr-075-G-X-04 & 2,3866 & 1,03 & 0,1979 & 0,60 & 0,58 & 5,0523 & 0,60 & 0,0875 & 0,84 & 0,72 \\
\hline $\mathrm{Zr}-075-\mathrm{G}-\mathrm{X}-05$ & 2,2357 & 1,23 & 0,1866 & 0,89 & 0,72 & 5,3603 & 0,89 & 0,0869 & 0,85 & 1,04 \\
\hline $\mathrm{Zr}-075-\mathrm{G}-\mathrm{X}-11$ & 2,4247 & 2,77 & 0,2097 & 2,57 & 0,93 & 4,7684 & 2,57 & 0,0839 & 1,03 & 2,49 \\
\hline $\mathrm{Zr}-075-\mathrm{G}-\mathrm{X}-12$ & 2,3320 & 2,00 & 0,1979 & 0,70 & 0,35 & 5,0528 & 0,70 & 0,0855 & 1,88 & 0,38 \\
\hline Zr-075-G-X-13 & 2,2744 & 1,66 & 0,1932 & 0,64 & 0,39 & 5,1767 & 0,64 & 0,0854 & 1,53 & 0,42 \\
\hline $\mathrm{Zr}-075-\mathrm{G}-\mathrm{X}-16$ & 2,5718 & 2,18 & 0,2203 & 1,65 & 0,76 & 4,5397 & 1,65 & 0,0847 & 1,42 & 1,17 \\
\hline $\mathrm{Zr}-075-\mathrm{G}-\mathrm{X}-20$ & 2,3467 & 1,55 & 0,2010 & 0,65 & 0,39 & 4,9745 & 0,65 & 0,0847 & 1,42 & 0,43 \\
\hline & \multicolumn{6}{|c|}{ Age $(\mathrm{Ma})$} & \\
\hline & ${ }^{206} \mathrm{~Pb} /{ }^{238} \mathrm{U}$ & \pm & ${ }^{207} \mathrm{~Pb} /{ }^{235} \mathrm{U}$ & \pm & ${ }^{238} \mathrm{U} /{ }^{206} \mathrm{~Pb}$ & \pm & ${ }^{232} \mathrm{Th} /{ }^{238} \mathrm{U}$ & \multicolumn{2}{|c|}{$\%$ Discor. } & F206 \\
\hline Zr-075-G-X-04 & 1164 & 7 & 1239 & 13 & 1370 & 11 & 15,74 & 15 & & 0,0001 \\
\hline Zr-075-G-X-14 & 1179 & 9 & 1218 & 18 & 1289 & 16 & 11,51 & 9 & & 0,0003 \\
\hline $\mathrm{Zr}-075-\mathrm{G}-\mathrm{X}-15$ & 1196 & 17 & 1246 & 21 & 1333 & 12 & 15,68 & 10 & & 0,0005 \\
\hline Zr-075-G-X-16 & 1283 & 21 & 1293 & 28 & 1308 & 19 & 16,45 & 2 & & 0,0001 \\
\hline Zr-075-G-X-20 & 1181 & $\frac{21}{7}$ & 1227 & 19 & 1308 & 19 & 10,91 & 10 & & 0,0002 \\
\hline
\end{tabular}



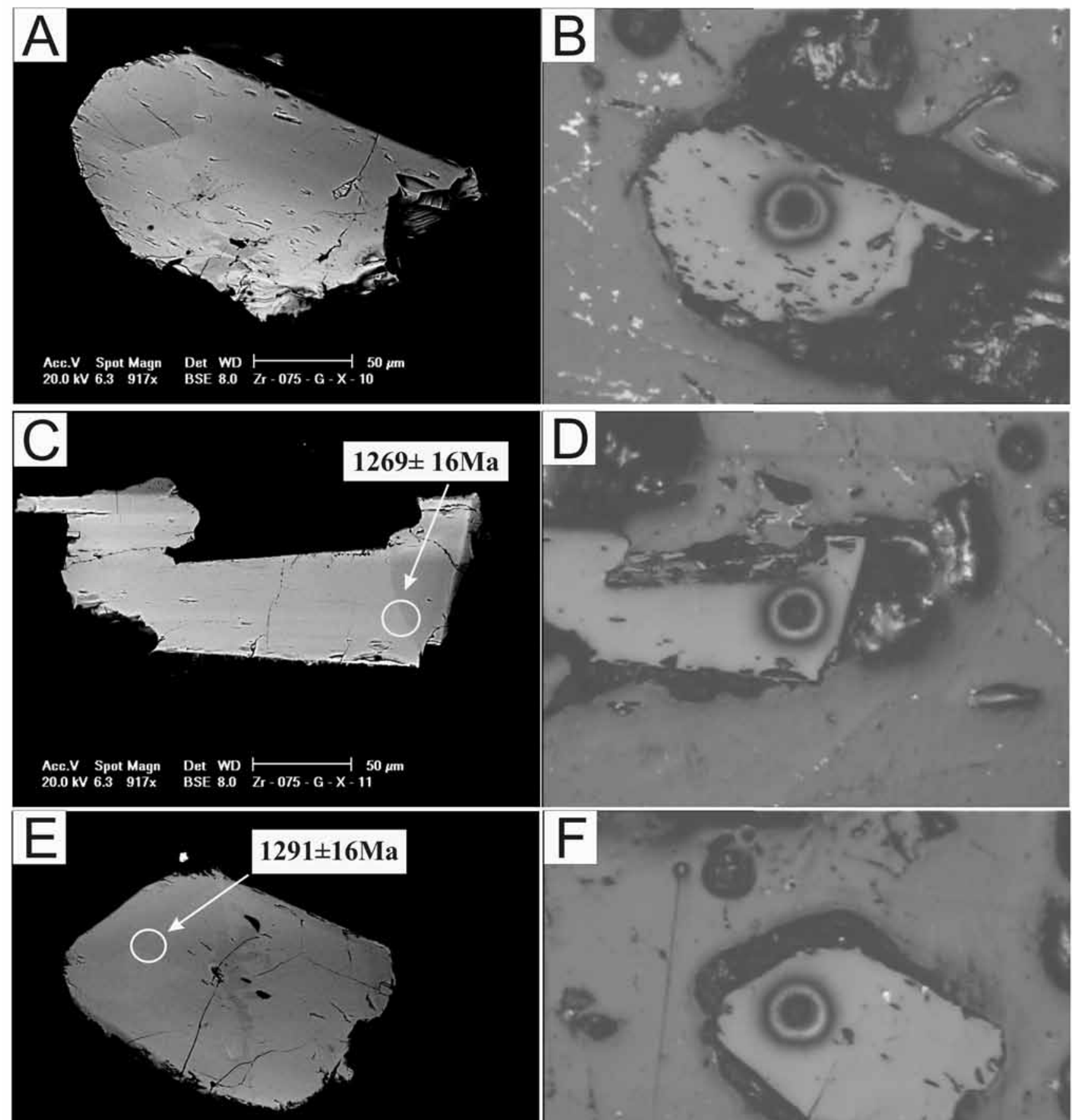

$\begin{array}{llll}\text { Ace.V } & \text { Spot Magn } & \text { Det WD } \\ 20.0 \mathrm{kV} & 6.3 & 886 \mathrm{x} & \text { BSE } 10.8 \mathrm{Zr}-075-\mathrm{G}-\mathrm{X}-16\end{array}$

Figura 13 - Imagens de Microscopia Eletrônica de Varredura (MEV) e fotos de microscopia óptica dos zircões, com spots de $25 \mu \mathrm{m}$ produzidos pela microssonda a laser, sendo $A$ e $B=Z r-075-G-X-10$, C e D $=Z r-$ $075-G-X-11$ e $E$ e $F=Z r-075-G-X-16$.

Tabela 4 - Dados de Sm-Nd para granito Passagem.

\begin{tabular}{c|c|c|c|c|c|c|c}
\hline $\begin{array}{c}\text { Unidade } \\
\text { Litoestratigráfica }\end{array}$ & Amostra & $\mathrm{Sm}(\mathrm{ppm})$ & $\mathrm{Nd}(\mathrm{ppm})$ & ${ }^{147} \mathrm{Sm} /{ }^{144} \mathrm{Nd}$ & $\begin{array}{c}143 \mathrm{Nd} / 144 \mathrm{Nd} \\
( \pm 2 \mathrm{SE})\end{array}$ & $\begin{array}{c}\epsilon_{\mathrm{Nd}(0)} \\
(\mathrm{GM})\end{array}$ \\
\hline Granito Passagem & $\mathrm{P} 2$ & 8.466 & 41,229 & 0,1241 & $0,512096 \pm 7$ & $-10,56$ & 1,60 \\
\hline
\end{tabular}





$20.0 \mathrm{kV} 6.3758 \times$ BSE 8.0 7r-075-G-X-04
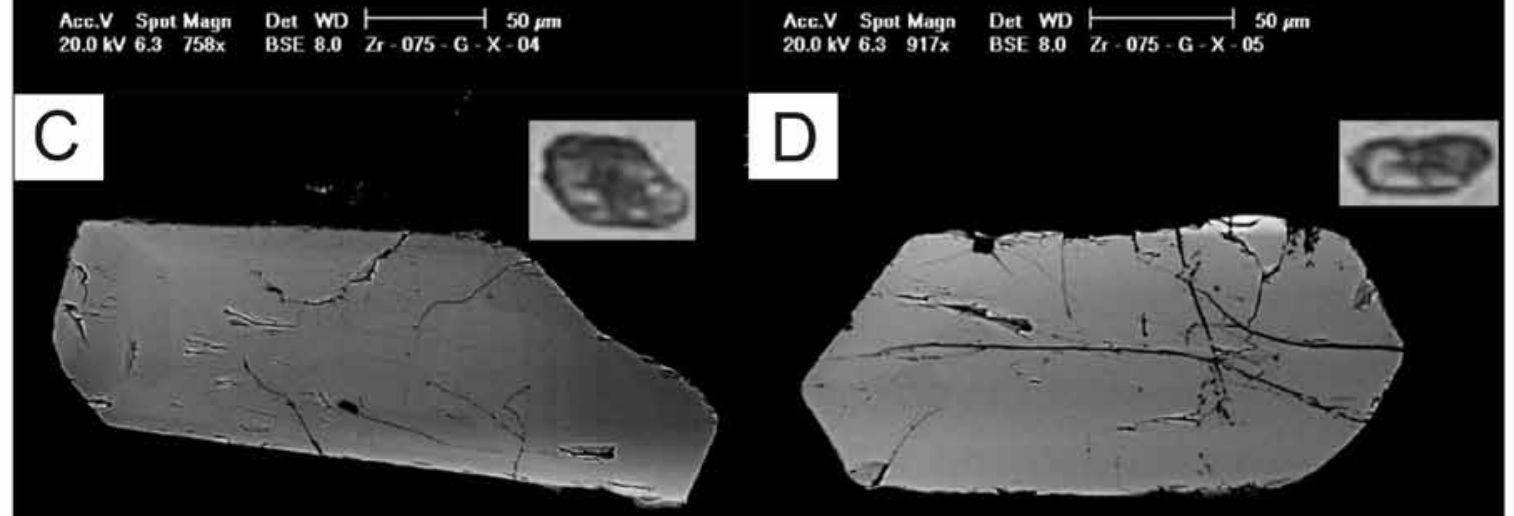

Ace.V Spot Magn Det WD $50 \mu \mathrm{m}$

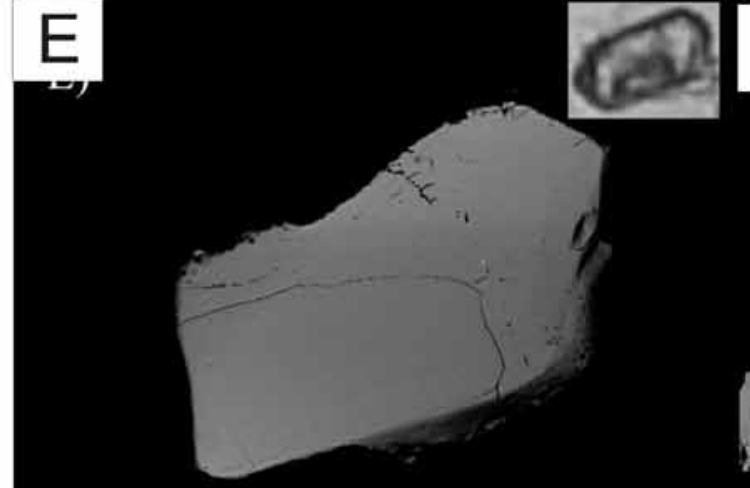

$\mathrm{E}$ $\begin{array}{lll}\text { Ace.V Spot Magn } & \text { Det WD } \\ 20.0 \mathrm{kV} & \mathbf{6 . 0} 71 \mathrm{x} & \mathrm{BSE} 10.7 \mathrm{Zr}-075-\mathrm{G}-\mathrm{X}-14\end{array}$

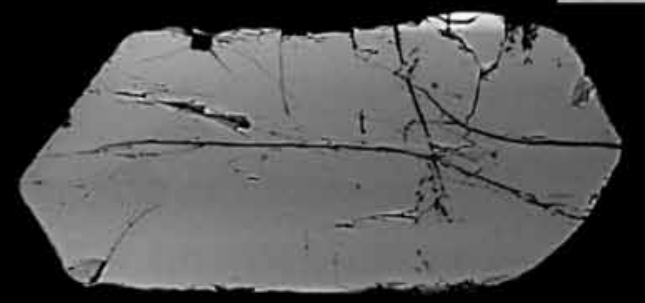

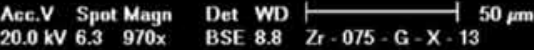


Aee.V Spat Magn Det wo

\section{G}



Figura 14 - Imagens de Microscopia Eletrônica de Varredura de cristais de zircão da amostra P2 e no detalhe imagens dos grãos ao microscópio óptico, sendo: A) Zr-075-G-X-04, B) Zr-075-G-

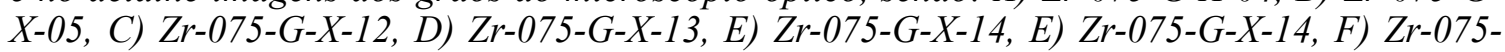
$075-G-X-15$, G) Zr-075-G-X-20. 


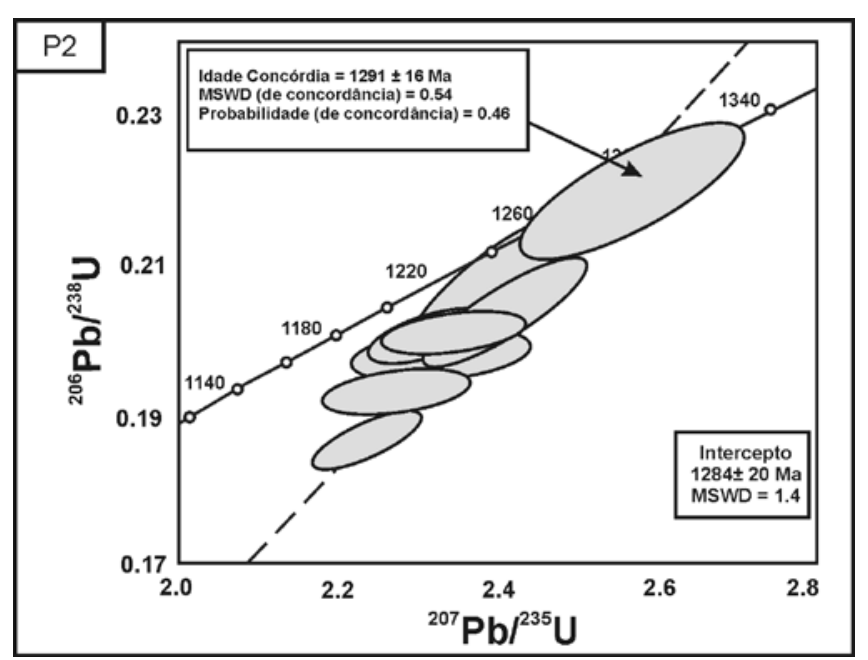

Figura 15 - Diagrama com dados de U/Pb em zircões $d a$ amostra P2 obtidos com LAM-MC-ICP-MS forneceram uma idade concordante de 1291 \pm 16 Ma e uma idade concórdia no intercepto superior de $1284 \pm 20 \mathrm{Ma}$.

subsolvus pela ocorrência simultânea de pertitas e plagioclásio sódico (albita ou oligoclásio) como fase isolada.

$\mathrm{O}$ estudo geoquímico classifica o magmatismo que originou os litotipos do granito Passagem como de caráter ácido, subalcalino, do tipo cálcio-alcalino de alto potássio, de natureza levemente peraluminosa, diferenciado por cristalização fracionada associada à contaminação crustal e gerado em ambiente de arco magmático provavelmente em época pós-colisional com uma temperatura de colocação por volta de $900^{\circ} \mathrm{C}$.

A idade $\mathrm{T}_{\mathrm{DM}}$ encontrada no estudo geocronológico sugere que o protólito magmático fracionou do manto por volta de $1600 \mathrm{Ma}$, durante o período Orosiriano, no Paleoproterozóico; o valor calculado negativo de $\varepsilon_{\mathrm{Nd}(1,29 \mathrm{Ga})}$, em torno de -7 , assinala a natureza híbrida do magma parental e corrobora a idéia de contaminação crustal; enquanto que o valor concordante de 1291 \pm 16 Ma e $1284 \pm 20$ Ma fornecidos pela análises de zircões correspondem, respectivamente, à provável idade de alojamento e de cristalização desse granito.

Os dados estruturais, geoquímicos e geocronológicos obtidos para o Granito Passagem permitem correlacioná-lo às intrusões tardi a pós-cinemáticas do Complexo Granitóide Pensamiento, conforme definição original de Litherland et al. (1986). A idade de cristalização (U-Pb laser ablation) de 1.29 Ga e a natureza indeformada a levemente deformada do Granito Passagem, sugerem a correlação desses corpos aos granitos Diamantina, Discordância, Porvenir e ao granófiro Piso Firme todos aflorantes no setor Norte do Complexo Granitóide Pensamiento em território boliviano (Litherland et al. 1986, Bettencourt et al. 2010).

Considerando a interação dos terrenos que compõem o arranjo tectônico no SW do Cráton Amazônico na Bolívia e em Mato Grosso (Brasil) e o acervo de dados obtidos e comparados aos disponíveis para os granitóides do Complexo Pensamiento, sugere-se que o magmatismo ácido representado pelo Granito Passagem, foi gerado em um arco magmático tipo andino, instalado às margens do Terreno Paraguá, durante a Orogenia San Ignácio (1350 a $1300 \mathrm{Ma}$ ), mais exatamente, na fase final deste ciclo orogênico. Provavelmente o magma parental foi gerado a partir do consumo de uma litosfera oceânica, cujos remanescentes encontram-se preservados no Terreno Rio Alegre (1.5 a $1.38 \mathrm{Ga})$.

Agradecimentos Os autores agradecem à FAPEMAT (Proc. 002.0141/2007) pelo custeio das análises químicas de rocha e pela concessão de bolsa de mestrado à primeira autora. Agradecimentos são devidos também à professora Dra. Ana Claudia Dantas da Costa e à mestra Maria Elisa Fróes Batata pelo auxílio na geocronologia.

\section{Referências}

Barros A.M., Silva R.H. da, Cardoso O.R.F.A., Freire F.A. Souza Jr. J.J.de, Rivetti M., Luz D.S. da, Palmeira R.C. \& Tassinari C.C.G.1982. Geologia. In: Projeto RADAMBRASIL, Folha SD. 21. Cuiabá. Rio de Janeiro, Levantamentos de Recursos Naturais, 26:25-192.

Barrett T. J. \& MacLean W. H. 1999. Volcanic Sequences,Lithogeochemistry, and Hidrothermal Alteration in Some Bimodal Volcanic-Associated Massive Sulfide Systems. Reviews in Economic Geology, 8:101-131.

Bettencourt J. S., Leite Jr. W.B., RUIZ A.S., Matos R., Payolla B.L., Tosdal R.M. 2010 The Rondonian-San Ignacio Province in the SW Amazonian Craton: An overview. Journal of South American Earth Sciences, 29:28-46.

Boger S.D., Raetz M., Giles D., Etchart E., Fanning C.M. 2005. $\mathrm{U}-\mathrm{Pb}$ age data from the Sunsas region of Eastern Bolivia, evidence for the allochthonous origin of the Paragua Block. Precambrian Research, 139: 121-146.

Cordani U.G., Tassinari C.C.G., Teixeira W., Basei M.A.S.,
Kawasita K.1979. Evolução tectônica da amazônia com base nos dados geocronológicos. In: Congresso Geológico Chileno, 2, Chile, Actas, p.137-48.

Cordani U.G. \& Teixeira W. 2007. Proterozoic accretionary belts of the Amazonian Craton. In: Hatcher R.D. Jr., Carlson M.P., Mcbride J.H., Martinez Catalan J.R. (org.) The 4 D Framework of Continental Crust. Boulder, Colo.: Geological Society of America, p. 297-320. (Memoir. v. 200).

Geraldes M.C. 2000. Geocronologia e geoquímica do plutonismo mesoproterozóico do SW do Estado de Mato Grosso (SW do Cráton Amazônico). Tese de Doutoramento, Instituto de Geociências, Universidade de São Paulo, São Paulo, 193 p.

Geraldes M.C. Van Schmus W.R. Condie K.C. Bell S. Teixeira W., Babinski M. 2001. Proterozoic geologic evolution of the SW part of the Amazonian Craton in Mato Grosso state, Brazil. Precambrian Research, 111:91-128.

Harris N.B.W., Pearce J.A., Tindal A.G. 1986. Geochemical characteristics of collision-zone magmatism. In: Coward 
M.P. \& Ries A.C. (ed.) Collision Tectonics. London-The Geol. Soc. Spec. Bull., 19:67-81.

Irvine T.N. \& Baragar W.R.A. 1971. A guide to the chemical classification of the common volcanic rocks. Can. J. Earth Sci., 8:523-548.

La Roche (de) H. 1980. Granites chemistry through multicationic diagrams. Sciences de la Terre, Série Informatique Géologique, 13:65-88.

Le Maitre R.W. 1989. A Classification of Igneous Rocks and Glossary of Terms: Recommendations of the International Union of Geological Sciences Subcommission on the Systematics of igneous rocks. Oxford, Blackwell, $193 \mathrm{p}$.

Litherland M., Annells R.N., Appleton J.D., Berrangé J.P., Bloomfield K., Burton C.C.J., Darbyshire D.P.F., Fletcher C.J.N., Hawkins M.P., Klinck B.A., Lanos A., Mithcell W.I., O Connor E.A., Pitfield P.E.J., Power G.E. Webb B.C. 1986. The Geology and Mineral Resources of the Bolivian Precambrian Shield. London, British Geological Survey, Her Majesty's Stationery Office, Overseas Memoir 9, 140 p.

Maniar P.D. \& Piccoli P.M. 1989. Tectonic discrimination of granitoids. Geol. Soc. Amer. Bull., 101:635-643.

Matos R., Teixeira W., Geraldes M. C., Bettencourt J.S. 2009. Geochemistry and Nd-Sr Isotopic Signatures of the Pensamiento Granitoid Complex, Rondonian-San Ignacio Province, Eastern Precambrian Shield of Bolivia: Petrogenetic Constraints for a Mesoproterozoic Magmatic Arc Setting. Revista do Instituto de Geociências USP. Geol. USP, Sér. cient., 9(2):89-117.

Middemost E.A.K. 1991. Towards a comprehensive classification of igneous rocks and magmas. Earth Science Reviews, 31:73-87.

Nakamura K. 1977. Volcanoes as a possible indicator of tectonic stress orientation: principle and proposal. J. Volcanol. Geotherm. Res., 2:1-16.

Peacock M.A. 1931. Classification of igneous rock series. Journal of Geology, 39:54-67.

Pearce J.A., Harris N.B.W., Tindle A.G. 1984. Trace element discrimination diagrams for the tectonic interpretation of granitic rocks. J. Petrol., 25(4):956-983.

Pearce J.A. 1996. Sources and settings of granitic rocks. Episodes, 19:120-125.

Ruiz A.S. 2005. Evolução Geológica do Sudoeste do Cráton Amazônico Região Limitrofe Brasil-Bolivia-Mato Grosso. Tese de Doutoramento, UNESP, Rio Claro, SP, 260 p.

Ruiz A.S. 2009. Compartimentação Tectônica (Pré-Sunsás) do Sudoeste do Cráton Amazônico: ênfase em Mato Grosso - Brasil. In: Congreso Geológico Boliviano, 18, Potosi, Comision Cientifica Nacional - Ing. Daniel Howard, Memórias, p. 159-163.

Ruiz A.S., Sousa M Z.A., Macambira M.B., Lima G.A., Santos F. 2009. Evidências Geológicas e Geocronológicas $(\mathrm{Pb}-\mathrm{Pb}$ e U-Pb) dos Episódios Magmáticos Lomas Manechis e San Ignácio no Terreno Paraguá - SW do Craton Amazônico Vila Bela (MT). In: Simpósio 45 Anos de Geocronologia no
Brasil, São Paulo, atas, p. 304-306.

Saes G.S. \& Fragoso César A.R.S. 1996. Acresção de terrenos mesoproteróicos no SW da Amazônia. In: SBG, Cong. Bras.Geol., 39, Salvador, Boletim de Resumos Expandidos, 1:124-126.

Saes G.S. 1999. Evolução tectônica e paleogeográfica do Aulacógeno Aguapei (1.2 - $1.0 \mathrm{Ga}$ ) e dos terrenos do seu embasamento na porção sul do Cráton Amazônico. Tese de Doutoramento, Instituto de Geociências, Universidade de São Paulo, São Paulo, 135 p.

Santos J.O.S., Hartmann L.A., Gaudette H.E., Groves D.I., Mcnaughton N.J., Fletcher I.R. 2000. A new understanding of the Amazon Craton Provinces based on integration of field mapping and U-Pb and $\mathrm{Sm}-\mathrm{Nd}$ geochronology. Gondwana Research, Japão, 3(4):453-488.

Santos J.O.S., Rizzotto G.J., Potter P.E., Mcnaughton N.J., Matos R.S., Hartmann L.A., Chemale Jr. F., Quadros M.E.S. 2008. Age and autochthonous evolution of the Sunsás Orogen in the West Amazon Craton based onmmapping and U-Pb greochronology. Precambrian Research, 165(34):120-152.

Scheepers R. 1995. Geology, geochemistry and petrogenesis of Late Precambrian S-, I- and A- type granitoids in the Saldania belt, Western Cape Province, South Africa. Journal of African Earth Sciences, 21(1):35-58.

Tassinari C.C.G. \& Macambira M.J.B. 1999. Geochronological provinces of the Amazonian Craton. Episodes, 38:174182.

Tassinari C.C.G., Bettencourt J.S., Geraldes M.C., Macambira M.J.B.,Lafon J.M. 2000. The Amazonian Craton. In: Cordani U.G.,Milani E.J., Thomaz Filho A., Campos D.A. (eds.) Tectonic Evolution of South America. Intern. Geol. Congr., 31 st, Rio de Janeiro, p. 41-95.

Tassinari C.G.C. \& Macambira M.J.B. 2004. A evolução tectônica do Cráton Amazônico. In: Neto-Mantesso V., Bartorelli A, Carneiro C.D.R., Brito-Neves B.B. de B. (Org.) Geologia do continente sul-americano: evolução da obra de Fernando Flávio Marques de Almeida, São Paulo, Editora Beca, p. 471-486.

Teixeira W. \& Tassinari C.C.G. 1984. Caracterização geocronológica da Província Rondoniana e suas implicações geotectônicas. In: SBG/Núcleo Norte, Symposium Amazonico, 2, Manaus, Anais, p. 87-101.

Watson E.B. \& Harrison T.M. 1984. Accessory minerals and the geochemical evolution of crustal magmatic systems: a summary and prospectus of experimental approaches. Physics of Earth and Planetary Interiors, 35:19-30.

Winchester J.A. \& Floyd P.A. 1977. Geochemical discrimination of different magma series and their differentiation products using immobile elements. Chem. Geol., 20:325-343.

Manuscrito ID16065 Submetido em 12 de novembro de 2009 Aceito em 15 de setembro de 2010 